NBER WORKING PAPER SERIES

\title{
THE POLITICS OF FREE TRADE AGREEMENTS
}

Gene M. Grossman Elhanan Helpman

Working Paper No. 4597

\section{NATIONAL BUREAU OF ECONOMIC RESEARCH 1050 Massachusetts Avenue \\ Cambridge, MA 02138 \\ December, 1993}

\begin{abstract}
We thank the National Science Foundation, the U.S.-Israel Binational Science Foundation, and the CEPR for financial support. Grossman also thanks the John S. Guggenheim Memorial Foundation, the Sumitomo Bank Fund, the Daiwa Bank Fund, and the Center of International Studies at Princeton University. Helpful comments from Raquel Fernandez, Paul Krugman, Torsten Persson, and Dani Rodrik are gratefully acknowledged. This paper is part of NBER's research program in International Trade and Investment. Any opinions expressed are those of the authors and not those of the National Bureau of Economic Research.
\end{abstract}


NBER Working Paper \#4597

December 1993

\title{
THE POLITICS OF FREE TRADE \\ AGREEMENTS
}

\begin{abstract}
Suppose that an opportunity arises for two countries to negotiate a free trade agreement (FTA). Will an FTA between these countries be politically viable? And if so, what form will it take? We address these questions using a political-economy framework that emphasizes the interaction between industry special interest groups and an incumbent government. We describe the economic conditions necessary for an FTA to be an equilibrium outcome, both for the case when the agreement must cover all bilateral trade and when a few, politically sensitive sectors can be excluded from the agreement.

Gene M. Grossman Woodrow Wilson School

Princeton University

Princeton, NJ 08544

and NBER

Elhanan Helpman

The Eitan Berglas School of Economics

Tel Aviv University

Tel Aviv, ISRAEL 69978 and NBER
\end{abstract}




\section{INTRODUCTION}

Governments have been meeting frequently of late to discuss the possibility of their forming bilateral or regional trading arrangements. The United States has negotiated bilateral agreements with Israel and Canada, and is pursuing additional accords with Mexico and perhaps Chile. The European Community expanded its membership to include Greece, Portugal, and Spain, and has discussed preferential arrangements with many Central and Eastern Europian countries. Some members of the Association for South East Asian Nations (ASEAN) have called for the formation of a Pacific free trade area. And Argentina, Brazil, Paraguay, and Uruguay have banded together to form the Southern Common Market (MERCOSUR).

These various discussions have never been easy, nor have they always been successful. One need only reflect on the recent debates in the United States and Canada over the NAFTA or those in Europe concerning accession to the EC or the lowering of barriers to trade with Eastern Europe to recognize the political hackles raised by prospective trading arrangements. Many political pressures are brought to bear on a government as it contemplates whether to enter into an agreement and what the provisions of such an agreement ought to be. In this paper we attempt to analyze some of these political forces. In particular, we ask: Suppose that an opportunity arises for two countries to negotiate a free trade agreement (FTA) among themselves. Will an FTA between these countries be politically viable? And if so, what form will the agreement take?

To address these questions, we use the framework of analysis that we developed in Grossman and Helpman (1994). This framework emphasizes the interaction between lobby groups representing industry special interests and an incumbent government. The lobby groups offer policy-contingent campaign contributions to the politicians, who seek to fulfill their own political objectives. In this setting, a country's policy stance reflects 
the relative political power of its various special interests and also the extent of its government's concern for the plight of the average voter.

In Grossman and Helpman (1993) we studied international negotiations over levels of non-discriminatory tariffs. We emphasized that international relations among politically-minded governments involve two stages of strategic interaction. First, a political competition in each country determines the government's policy preferences. Then a give-and-take between governments determines the international equilibrium. The politics leading up to a potential free trade agreement are similar in this regard, but they differ from those that determine countries' tariff schedules in at least one important respect. When individual tariff rates are set on many different goods, the main political battles are between the export interests in one country and the importcompeting interests in the other country active in the same industry. The former group lobbies for low tariffs in the importing country, while the latter group demands high barriers to trade. In contrast, when an FTA will drop many or all (bilateral) tariff rates to zero, the negotiations pit the export interests in a country directly against the import-competing interests in the same country. The potential exporters covet preferential access to the partner's market, while the import-competing industries aim to preserve their protection by scuttling any agreement.

The paper is organized as follows. Section 2 develops the analytical framework, describing both the economic and political interactions, and the effects of an FTA on the welfare of various agents. In Section 3 we focus on a single country, asking when its government might endorse an agreement calling for complete and immediate liberalization of all bilateral trade with some partner. This forms the basis for our discussion in Section 4 of the outcome of a bilateral negotiation between two countries. There, we highlight the economic conditions necessary for an FTA covering all trade to be viable as an equilibrium outcome. In Section 5 we allow for the possibility that an FTA may exclude a few, especially sensitive sectors, or that it may at least allow for 
some extended periods of adjustment. We show how a more liberal interpretation of GATT rules about the types of permissible FTAs may enhance political viability and we illustrate how the international bargaining process determines the terms of an agreement. The concluding section summarizes our main findings.

\section{ANALYTICAL FRAMEWORK}

We examine the trade policy of two small countries, A and B, that interact with one another and the rest of the world. The countries produce and trade many goods, all of whose international prices are normalized to one. Initially, each country imposes the same tariff on all imports of a good regardless of source, in keeping with the Most Favored Nation (MFN) clause of the GATT Articles of Agreement. The two countries now have the opportunity to negotiate an FTA together. Our aim is to identify the political and economic conditions in the two countries that would make it possible for their politically-minded governments to conclude such an agreement.

We suppose that there is a numeraire good 0 that is untaxed in each country and $n$ other goods. Some of these goods are imported by one or both of the small countries in the initial equilibrium, while others may be exported. In keeping with GATT rules, we exclude the possibility that the countries subsidize their exports. We also ignore export taxes, which are unconstitutional in the United States and rarely used elsewhere. Thus, we assume that the initial domestic price in either country of any good that is exported by that country is one. As for import goods, these may be subject to arbitrary import tariffs. We let $\tau_{j}^{j}$ represent one plus the initial tariff rate on good $i$ in country $j$. With our normalization of international prices, these are also the domestic prices in country $j$ for the import goods. 1

1 We adopt the convention that $\tau_{i}^{j}=1$ for the numeraire good 0 and for any goods that 
Article XXIV of the GATT Articles of Agreement permits certain exceptions to the principle of MFN. Countries may enter bilateral or regional agreements if they eliminate "duties and other regulations of commerce" on "substantially all trade" among themselves. The GATT rules allow for both customs unions, in which member countries impose a common external tariff on trade with the rest of the world, and free trode areas, in which the countries maintain separate external tariffs and enforce them with rules of origin. In this paper we study only the latter type of agreement. GATT rules further stipulate that the external tariffs imposed after the conclusion of an FTA must be no higher than those that were in force beforehand. Accordingly, we suppose that the initial tariffs $\tau_{j}^{j}$ continue to apply to imports from the rest of the world under any FTA that might be contemplated.

The phrase "substantially all trade" in GATT Article XXIV has been interpreted to allow some latitude in the structuring of trade agreements. Regional and bilateral trade agreements typically exclude a few politically-sensitive sectors and specify a prolonged phase-in period for some others. At first, we shall ignore this limited degree of flexibility and interpret the GATT rules as requiring that all goods be freely traded between the parties to any agreement. But later we will relax this assumption, and suppose that the countries can exclude an exogenous (but presumably small) number of sectors from the agreement. Then we will have the initial MFN tariffs remain in force on trade between $A$ and $B$ in the excluded goods.

\subsection{Objectives of Economic and Political Agents}

The qualitative features of the two small economies are similar, although the particular conditions may differ. We describe the structure of one of the countries, but

are exported by country $j$ in the initial equilibrium. Then we can use $\tau^{j}=\left(r_{0}^{j}, r_{1}^{j}, \ldots, \tau_{n}^{j}\right)$ to represent the vector of initial domestic prices in country $j$. 
omit for the time being the country superscripts that implicitly are attached to every function and variable.

The country has a population normalized to one. Individuals within the country have identical preferences $u(c)=c_{0}+\Sigma_{i=1}^{n} u_{i}\left(c_{j}\right)$, where $c_{i}$ denotes consumption of good $i$ and $u_{\mathfrak{i}}(\cdot)$ is an increasing and concave function. These preferences give rise to the per capita demands $D_{i}\left(q_{i}\right)$ for goods $i=1, \ldots, n$ and the demand $y-\Sigma_{i=1}^{n} q_{i} D_{i}\left(q_{j}\right)$ for $\operatorname{good} 0$, where $q_{i}$ is the domestic consumer price of good $i$ and $y$ is the individual's spending. The same demands apply in the aggregate, except that individual spending is replaced by aggregate spending in the demand for good 0 .

Good 0 is manufactured by labor alone, with one unit of labor required per unit of output. Each other good is produced with constant returns to scale by labor and a sector-specific factor. Since the domestic price of good 0 has been normalized to one, the competitive wage rate must equal one in any equilibrium in which this good is produced. Then the specific factor used in industry $i$ earns the reward $\Pi_{i}\left(p_{i}\right)$, where $p_{i}$ is the domestic producer price and $\Pi_{j}^{\prime}(\cdot)>0$. Aggregate supply of good $i$ is $X_{i}\left(p_{i}\right)=\Pi_{i}^{\prime}\left(p_{i}\right)$ for $i=1, \ldots, \mathrm{n}$, and net imports are $\mathrm{M}_{\mathrm{i}} \equiv \mathrm{D}_{\mathrm{i}}\left(\mathrm{q}_{\mathrm{i}}\right)-\mathrm{X}_{\mathrm{i}}\left(\mathrm{p}_{\mathrm{i}}\right)$, which may be positive or negative.

We assume that the ownership of the specific factors is bighly concentrated in the population. In fact, we take an extreme case where these factor owners comprise a negligible fraction of the total number of voters. The owners of a particular factor have a common interest in seeing a high domestic price for the good they produce, and so favor protection from foreign competition. We assume, perhaps because they are few in number, that they can overcome the "collective action problem" described by Olson (1965) and that they work together for their common political goals. The owners of the factor used in sector $i$ form a special interest group that takes political action in order to 
maximize their joint welfare. ${ }^{2}$

As in Grossman and Helpman $(1993,1994)$, we suppose that the incumbent government is in a position to set trade policy, which means here that it can either work toward a free trade agreement or terminate the discussions. The politicians may receive contributions from the various interest groups hoping to influence its decision. The politicians value these contributions - because they help them to get reelected or for other reasons - but they also may care about the well being of the average voter. Per capita welfare will enter the incumbent government's objective function, for example, if some voters are well informed about the effects of trade policy and base their vote partly on their standard of living. We assume that the government's objective has a simple linear form, $G \equiv \Sigma_{i} C_{i}+a W$, where $C_{i}$ is the campaign contribution of the lobby representing industry $i, W$ is aggregate (and per capita) welfare, and $a$ is a parameter (possibly zero) reflecting the government's sensitivity to the average voter's well being relative to its taste for campaign contributions. ${ }^{3}$

Each individual in the economy enjoys surplus of $S_{i}\left(q_{i}\right) \equiv u_{i}\left[D_{i}\left(q_{i}\right)\right]-q_{i} D_{i}\left(q_{i}\right)$ from consuming good $i, i=1, \ldots, \mathrm{n}$. Each individual also receives a lump-sum transfer from the government, representing his or her share of the tariff revenue, which we take to be redistributed evenly to the entire population. Therefore, the aggregate welfare of voters is given by

$$
\mathrm{W}=\mathrm{L}+\Sigma_{\mathrm{i}=1}^{\mathrm{n}} \Pi_{\mathrm{i}}\left(\mathrm{p}_{\mathrm{i}}\right)+\Sigma_{\mathrm{i}=1}^{\mathrm{n}}\left(\tau_{\mathrm{i}}-1\right) \mathrm{M}_{\mathrm{i}}+\Sigma_{\mathrm{i}=1}^{\mathrm{n}} \mathrm{S}_{\mathrm{i}}\left(\mathrm{q}_{\mathrm{i}}\right)
$$

${ }^{2}$ In Grossman and Helpman $(1993,1994)$ we allow for the possibility that some industries may fail to organize for political action, although we take the set of organized lobbies as exogenous in our analysis. Here, for simplicity, we assume that all sectors are organized.

3 Alternatively, we could use the welfare of the median voter, rather than that of the mean voter, as an argument in the government's objective function. The difference is that the median individual owns none of any industry specific factor. The analysis would proceed similarly, except that $W$ would be defined in (2) to exclude aggregate profits. See Grossman and Helpman (1994) for further discussion of the government's objective function. 
where $\mathrm{L}$ is the aggregate labor supply and the right-hand side of (2) therefore represents the sum of aggregate labor income, aggregate profits, total tariff revenues, and aggregate consumer surplus.

Note that the small number of owners of the input used in industry $i$ capture a negligible fraction of the total consumer surplus in the economy and they receive only a negligible fraction of the rebated tariff revenue. Thus, the objective of these factor owners can be approximated quite closely by $\Pi_{j}\left(p_{i}\right)-C_{i}$, their profits net of political contributions. We will use $\Pi_{\mathrm{iN}}$ to represent their profits in the event that no agreement is reached, in which case their output continues to sell for $\mathrm{p}_{\mathrm{i}}=\tau_{\mathrm{i}}$. Similarly, we let $\Pi_{\mathrm{iF}}$ denote the profits of industry $i$ in the event of an FTA, which depend of course on the equilibrium producer prices that would prevail under such an agreement. In a moment, we will consider what these equilibrium prices must be; but first we describe the nature of the political game.

\subsection{The Political Game}

Interest groups move first in the political game by offering financial support to the incumbent politicians. The groups make their contributions contingent on the actions taken by the government with respect to the trade agreement. This follows Grossman and Helpman (1994), where we applied Bernheim and Whinston's (1986) notion of a menu auction to the problem of tariff formation. In our earlier paper, we allowed interest groups to design contribution schedules linking every trade tax vector that the government might implement to a proposed campaign gift. Here the government has only two options: to pursue an accord or not. It follows that a contribution schedule need only comprise two numbers, $\mathrm{C}_{\mathrm{iF}}$ and $\mathrm{C}_{\mathrm{iN}}$, which are the gifts associated with the realization of an FTA and with a continuation of the status quo, respectively.

In fact, it is never optimal for a lobby to promise positive gifts for both policy 
outcomes, because then it could cut back equally on both of its offers without affecting the government's decision. And a lobby surely does not wish to give the government any added incentive to choose the outcome that is contrary to its interests. Thus, each lobby needs to quote only a single number, representing its donation in the event that its preferred outcome is chosen. We limit each lobby to offer no more than what it stands to gain in profits if the government were to follow its bidding. 4

The lobbies set their contributions noncooperatively. Then, faced with the set of offers $\left\{\left(\mathrm{C}_{\mathrm{iF}}, \mathrm{C}_{\mathrm{iN}}\right)\right\}$, the government takes a position on the trade accord. The government endorses the agreement if its political objective function is higher with the FTA than without; that is, if $\Sigma_{i} C_{i F}+a W_{F} \geq \Sigma_{i} C_{i N}+a W_{N}$ (where $W_{R}$ is aggregate welfare under regime $R, R=F, N)$. Otherwise, it rejects the agreement.

\subsection{Economic Equilibrium Under an FTA}

Before we can proceed to characterize the outcome to this political game, we must discuss what effects the FTA would have on the voters and special interest groups in each country. Our economic analysis builds on Richardson (1992).

We focus on one particular product i. If both countries happen to export this good in the initial equilibrium, then each has a domestic price equal to one, and the FTA will have no effect on outputs, profits, or consumption levels. The more interesting cases arise when at least one of the countries initially imports the good subject to a positive MFN tariff. Without loss of generality we consider an industry where $\tau_{i}^{A}>\tau_{i}^{B} \geq 1$.

Figure 1 depicts the demand for imports by country $A$ and three possible locations of the total supply curve for country B. Suppose that B's endowment of the specific factor is relatively small, as with $\mathrm{X}_{\mathrm{i}}^{\mathrm{B}_{[}}[1]$, so that the total amount of that country's

4For every lobby, the strategy of bidding zero for all outcomes weakly dominates the strategy of bidding in excess of what the lobby stands to gain under its preferred regime. Our assumption rules out weakly dominated strategies. 
supply at price $\tau_{i}^{A}$ does not suffice to satisfy $A^{\prime} B$ import demand at that price. Then $A$ must continue to import from the rest of the world and its domestic price under an FTA remains at $\tau_{i}^{A}$. The producers in $B$ prefer to sell in $A$ 's market at the high price $\tau_{i}^{A}$, rather than at the lower price $\tau_{i}^{B}$ (which may equal one, if this is initially an export good) prevailing at home. In this case, these producers divert all of their output to country A after the conclusion of the FTA, and consumers in B satisfy all of their demands by importing from the rest of the world. The FTA has no effect on producer or consumer prices in country A, or on consumer prices in country B. It serves only to raise the prices paid to producers in the low-tariff country, who in effect capture the protection of the high-tariff country (see Krueger, 1993, on a related point). We will refer to this as the case of enhanced protection.

At the opposite extreme, the endowment of the specific factor in B may be so large that the industry output would satisfy $A^{\prime}$ 's import demand at the lower price $\tau_{i}^{B}$. In this case, represented by $\mathrm{X}_{\mathrm{i}}^{\mathrm{B}}[3]$ in the figure, the domestic price in country $A$ falls to $\tau_{\mathrm{i}}^{\mathrm{B}}$. Now B is the source for all of A's imports and producers in country B also supply at least part of their home market. Consumers in $B$ pay $\tau_{i}^{B}$ for the good just as they did before the agreement, and producers there continue to receive this sum. But producers in $A$ receive less than before, so this is a case of reduced protection.

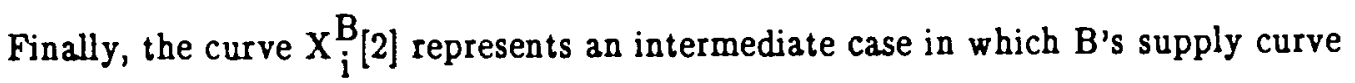
intersects $A$ 's import demand at a price between $\tau_{i}^{A}$ and $\tau_{i}^{B}$. In this case, when producers in $B$ divert their output to the higher priced market, this output is just sufficient to meet import demand at a price where there is no residual demand for imports from the rest of the world. Producers in B receive the equilibrium price in A's market, which is higher than $\tau_{i}^{B}$ but lower than $\tau_{i}^{A}$. Consumers in B import from the rest of the world, paying the same price $\tau_{i}^{B}$ as they did before the agreement.

The main point here is that, depending on the size of B's potential output, the marginal good produced there may be sold in A's protected market, in B's less protected 
market, or possibly even on the world market. The price that B's producers receive and that all agents face in country $A$ varies accordingly. Table 1 summarizes these findings.

\subsection{Effects of an FTA on Economic Interests}

We are now ready to describe how an FTA affects the profits of specific factor owners and the welfare of the average voter in each country. We continue to focus on a single industry in which $\tau_{i}^{A}>\tau_{i}^{B} \geq 1$. Of course the effect of an agreement on aggregate welfare reflects the sum of its effects in the various industries, including those in which $\tau_{\mathrm{i}}^{\mathrm{B}}>\tau_{\mathrm{i}}^{\mathrm{A}} \geq 1,5$

Consider first an industry that experiences enhanced protection. Producers in country $B$ benefit from their preferential access to A's highly protected market. We can write their gain as $\Delta \Pi_{i}^{B}=\Pi_{i}^{B}\left(\tau_{i}^{A}\right)-\Pi_{i}^{B}\left(\tau_{i}^{B}\right)$. Producers in $A$ are unaffected, since the domestic price there does not change. As for welfare, the only effect in $A$ is the loss of tariff revenue. This country, which collects duties on all of its imports in this industry under the MFN tariff, does not collect any on its imports of $X_{i}^{B}\left(\tau_{i}^{A}\right)$ from its partner under the FTA. The welfare change in $A$ amounts to $\Delta W_{i}^{A}=-\left(\tau_{i}^{A}-1\right) X_{i}^{B}\left(\tau_{i}^{A}\right)$. This welfare loss corresponds, of course, to the adverse effects of trade diversion, which are familiar from the literature on customs unions.

In country $B$ the contribution of the industry under consideration to aggregate welfare rises. There are two components of this gain. First, as we have noted, profits in the industry increase. Second, the country now imports from the rest of the world to replace the sales formerly made by domestic producers. Assuming that $\tau_{i}^{B}>1$, the country collects added tariff revenue on these new imports. The change in welfare equals $\Delta \mathrm{W}_{\mathrm{i}}^{\mathrm{B}}=\Delta \mathrm{\Pi}_{\mathrm{i}}^{\mathrm{B}}+\left(\tau_{\mathrm{i}}^{\mathrm{B}}-1\right) \mathrm{X}_{\mathrm{i}}^{\mathrm{B}}\left(\tau_{\mathrm{i}}^{\mathrm{B}}\right)$. We note that $\mathrm{A}$ 's welfare loss exceeds $\mathrm{B}^{\prime} \mathrm{s}$

5 That is, aggregate welfare can be written as $W=L+\Sigma_{i} W_{i}$, where $W_{i} \equiv \Pi_{j}\left(p_{i}\right)+T_{i}+$ $S_{i}\left(q_{i}\right)$ and $T_{i}$ is the tariff revenue collected on imports of good $i$. Then the change in $W$ is the sum of the changes in the $\mathrm{W}_{\mathrm{i}}$ 's. 
welfare gain, reflecting the global efficiency cost associated with trade diversion. ${ }^{6}$

For an industry that experiences reduced protection, the price obtained by producers in the low-tariff country does not change. These producers gain nothing from the agreement, while the producers in country $A$ suffer from the increased import competition. The expression for the profit change is $\Delta \Pi_{i}^{A}=\Pi_{i}^{A}\left(\tau_{i}^{B}\right)-\Pi_{i}^{A}\left(\tau_{i}^{A}\right)<0$. Tariff revenue from the industry falls to zero in country $A$, as all imports now originate in the partner country. But voters gain qua consumers from the fall in the domestic price of the good. The contribution of the industry to the change in aggregate welfare is $\Delta W_{i}^{A}=\Delta \Pi_{i}^{A}-\left(\tau_{i}^{A}-1\right) M_{i}^{A}\left(\tau_{i}^{A}\right)+S_{i}^{A}\left(\tau_{i}^{B}\right)-S_{i}^{A}\left(\tau_{i}^{A}\right)$, which may be positive or negative depending on the relative sizes of the gains from trade creation and the losses from trade diversion. Country $B$ captures only the extra tariff revenue in this case $\left[\Delta \mathrm{W}_{\mathrm{i}}^{\mathrm{B}}=\left(\tau_{\mathrm{i}}^{\mathrm{B}}-1\right) \mathrm{M}_{\mathrm{i}}^{\mathrm{A}}\left(\tau_{\mathrm{i}}^{\mathrm{B}}\right)\right]$, but joint welfare gains for the two countries together are assured.?

The intermediate case combines elements of the other two. Producers gain in country B and lose in country A. Aggregate welfare rises in B and may rise or fall in A. The effect on joint welfare of the two countries is ambiguous. As there is nothing new in this case, we will not consider it any further.

To summarize, an FTA can have any of several combinations of impacts on the economic actors with interests in a particular industry. Producers in the country that

- Since the profit functions are convex and their derivatives give the supplies, we know that $\Pi_{i}^{\mathrm{B}}\left(\tau_{\mathrm{i}}^{\mathrm{A}}\right)-\Pi_{\mathrm{j}}^{\mathrm{B}}\left(\tau_{\mathrm{i}}^{\mathrm{B}}\right)<-\mathrm{X}_{\mathrm{i}}^{\mathrm{B}}\left(\tau_{\mathrm{i}}^{\mathrm{A}}\right)\left(\tau_{\mathrm{i}}^{\mathrm{B}}-\tau_{\mathrm{i}}^{\mathrm{A}}\right)$. Then the fact that $\tau_{\mathrm{i}}^{\mathrm{A}}>\tau_{\mathrm{i}}^{\mathrm{B}}$ implies $\Delta \mathrm{W}_{\mathrm{i}}^{\mathrm{A}}+\Delta \mathrm{W}_{\mathrm{i}}^{\mathrm{B}}<\left(\tau_{\mathrm{i}}^{\mathrm{B}}-1\right)\left[\mathrm{X}_{\mathrm{i}}^{\mathrm{B}}\left(\tau_{\mathrm{i}}^{\mathrm{B}}\right)-\mathrm{X}_{\mathrm{i}}^{\mathrm{B}}\left(\tau_{\mathrm{i}}^{\mathrm{A}}\right)\right]<0$.

7 The convexity of the profit and consumer surplus functions implies $\Delta \Pi_{i}^{A}>$ $\mathrm{X}_{\mathrm{i}}^{\mathrm{A}}\left(\tau_{\mathrm{i}}^{\mathrm{A}}\right)\left(\tau_{\mathrm{i}}^{\mathrm{B}}-\tau_{\mathrm{i}}^{\mathrm{A}}\right)$ and $\mathrm{S}_{\mathrm{i}}^{\mathrm{A}}\left(\tau_{\mathrm{i}}^{\mathrm{B}}\right)-\mathrm{S}_{\mathrm{i}}^{\mathrm{A}}\left(\tau_{\mathrm{i}}^{\mathrm{A}}\right)>-\mathrm{D}_{\mathrm{i}}^{\mathrm{A}}\left(\tau_{\mathrm{i}}^{\mathrm{A}}\right)\left(\tau_{\mathrm{i}}^{\mathrm{B}}-\tau_{\mathrm{i}}^{\mathrm{A}}\right)$ in view of the fact that the derivatives of these functions are the supply and minus the demand function, respectively. These inequalities in turn imply $\Delta W_{i}^{A}+\Delta W_{i}^{B}>\left(\tau_{i}^{B}-1\right)\left[M_{i}^{A}\left(\tau_{i}^{B}\right)-\right.$ $\left.\mathrm{M}_{\mathrm{i}}^{\mathrm{A}}\left(\tau_{\mathrm{i}}^{\mathrm{A}}\right)\right]>0$, where the latter inequality follows from the fact that $\tau_{\mathrm{i}}^{\mathrm{B}}<\tau_{\mathrm{j}}^{\mathrm{A}}$. 
exports to its partner under an FTA sometimes gain and never lose. These producers are one potential source of political support for an agreement. On the other hand, the producers in the country that imports from its partner under the agreement never gain and sometimes lose. Here we find potential resistance. The stake of the general public in an FTA is less clearcut. If most goods will be exported to the partner, than aggregate welfare must rise, as consumer surplus never falls in the exporting country and tariff revenues generally increase. If most goods will be imported, the aggregate welfare effect depends on the relative strength of the forces of trade creation and trade diversion, as is well known from the theory of discriminatory tariffs.

\section{UNILATERAL STANCES}

The structuring of a free trade agreement typically involves lengthy negotiations between prospective partners. The negotiating parties often haggle over the length of the adjustment periods for sensitive sectors and perhaps a list of goods that will be excluded from the agreement altogether. We will take up some of these bargaining issues in Section 5. But first we consider a simpler case where the terms of the prospective FTA are fixed. Here the countries must agree to an across-the-board liberalization of their bilateral trade, or there is no agreement at all.

We begin by examining the political interactions in a single country. These determine the nation's unilateral stance; that is, the position the government would adopt if it expected that its decision would determine the fate of the agreement. We wish to describe the positions that can be supported as optimal government responses to equilibrium behavior by the country's interests groups. To this end, we propose the following definition: 
Definition: A choice of regime $R \in\{N, F\}$ is a unilateral stance if there exists a set of political contributions $\left\{\mathrm{C}_{\mathrm{iN}}, \mathrm{C}_{\mathrm{iF}}\right\}$, one for each lobby $i$, such that:

(a) $C_{i K} \geq 0$ for $K=N, F$ and for all $i$;

(b) $\quad C_{i K} \leq \max \left(0, \Pi_{i K}-\Pi_{i J}\right)$ for $J=N, F ; K=N, F ; J \neq K$;

(c) $\quad \Sigma_{i} C_{i R}+a W_{R} \geq \Sigma_{i} C_{i K}+a W_{K}$ for $K=N, F$;

(d) for every lobby $i$ there exist no contributions $\dot{\mathrm{C}}_{\mathrm{iN}} \geq 0$ and $\dot{\mathrm{C}}_{\mathrm{iF}} \geq 0$ and no regime $\hat{R}_{i} \in\{N, F\}$ such that:

(i) $\dot{\mathrm{C}}_{\mathrm{i} \hat{\mathrm{R}}_{\mathrm{i}}}+\Sigma_{\mathrm{j} \neq \mathrm{i}} \mathrm{C}_{\mathrm{jR}} \hat{\mathrm{R}}_{\mathrm{i}}+\mathrm{a} \mathrm{W}_{\hat{\mathrm{R}}_{\mathrm{i}}} \geq \dot{\mathrm{C}}_{\mathrm{iK}}+\Sigma_{\mathrm{j} \neq \mathrm{i}} \mathrm{C}_{\mathrm{jK}}+\mathrm{a} \mathrm{W}_{\mathrm{K}}$ for $\mathrm{K}=\mathrm{N}, \mathrm{F} ;$ and (ii) $\Pi_{i \hat{R}_{i}}-\hat{C}_{i \hat{R}_{i}}>\Pi_{i R}-C_{i R}$

The definition stipulates that the political contributions supporting a unilateral stance must be non-negative and no greater for any lobby than what it stands to gain under its preferred regime. The contributions must induce the government to take the position $R$ rather than the alternative, in the light of its own political objectives. Moreover, there should be no alternative offers available to any lobby that, given the contribution schedules of the other lobbies and the anticipated optimization by the politicians, would leave the lobby with higher net welfare.

We will find that there are two generic types of unilateral stances that may exist for a given set of parameter values. We refer to a stance as unpressured if the government takes the position despite there being no offers of contributions that encourage it to do so. By contrast, a pressured stance is one that the government takes partly in response to offers of support. We establish that 
Result 1: There exists an unpressured stance in support of regime $\mathrm{R}$ if and only if

$$
a\left(W_{R}-W_{\tilde{R}}\right) \geq \max \left[0, \max _{i}\left(\Pi_{i \tilde{R}}-\Pi_{i R}\right)\right]
$$

where $\ddot{\mathrm{R}}$ is the alternative to regime $\mathrm{R}$.

This result says that, in an unpressured stance, the government must prefer the regime $\mathrm{R}$ to the alternative $\tilde{\mathrm{R}}$ on grounds of aggregative welfare. Moreover, there should be no single lobby $i$ favoring the alternative $\tilde{R}$ that stands to lose so much under $R$ that it could unilaterally sway the government from its concern for the public interest.

The proof is straightforward. First, suppose that all contribution offers are zero; i.e., $\mathrm{C}_{\mathrm{iR}}=\mathrm{C}_{\mathrm{i} \tilde{\mathrm{R}}}=0$ for all $i$. Then the government will choose the socially preferred position and, if (3) is satisfied, no single lobby will fnd it profitable given the zero offers of the others to induce the government to change its stance. This establishes that ( 3 ) is sufficient for an unpressured stance in favor of $R$. As for necessity, it is obvious that we must have $W_{R}-W_{\tilde{R}} \geq 0$ if the government is to choose $R$ in the absence of any contributions in support of that position. And if $a\left(W_{R}-W_{\tilde{R}}\right)<\Pi_{i \tilde{R}}-\Pi_{i R}$ for any $i$, then lobby $i$ could profitably deviate by bidding something more than $a\left(W_{R}-W_{\tilde{R}}\right)$ but less than $\Pi_{i \tilde{R}}-\Pi_{i R}$, thereby inducing the government to choose $\tilde{R}$.

If the average voter is indifferent to the FTA, or close to it, then no unpressured stance will exist. For then, whatever stance the government might contemplate taking on behalf of voters can be blocked by a single lobby on the opposing side. Clearly there can exist at most one unpressured stance, since only one regime is the socially preferred outcome.

Next we examine unilateral stances that feature active lobbying on behalf of the chosen regime $\mathrm{R}$. With $\mathrm{C}_{\mathrm{iR}}>0$ for at least one lobby $i$, the government must be left 
indifferent between the alternative regimes; i.e., $\Sigma_{i} C_{i R}+a W_{R}=\Sigma_{i} C_{i \tilde{R}}+a W_{\tilde{R}}$. Otherwise, one of the lobbies offering a positive contribution in support of $R$ could reduce its offer without affecting the final outcome, thereby increasing its net profit. But once we know that the government is left indifferent, we also know that every lobby on the losing side (i.e., those preferring $\tilde{R}$ to $R$ ) must be bidding for $\tilde{R}$ the full amount of what it stands to lose under $R$; otherwise one such lobby would find it profitable to raise its offer for $\tilde{R}$ slightly, thereby tipping the balance to that policy. Of course, no lobby on the winning side offers more than the extra profits it earns under $R$. Since each lobby contributes nothing if the government's choice is counter to its interests, we have established

Result 2. If there exists a pressured stance in support of regime $\mathrm{R}$, then

$$
\Sigma_{i} \Pi_{i R}+a W_{R} \geq \Sigma_{i} \Pi_{i \tilde{R}}+a W_{\tilde{R}}
$$

Condition (4) states that the regime supported in a pressured stance maximizes the sum of aggregate profits and a times average welfare. It follows that, if such a stance exists, the policy outcome it selects is (generically) unique. Existence requires

$$
a W_{R}<a W_{\tilde{R}}+\sum_{i \in S_{\tilde{R}}}\left(\Pi_{i \bar{R}}-\Pi_{i R}\right)
$$

where $S_{\tilde{R}}$ is the set of lobbies that prefers regime $\tilde{R}$, and $R$ is the regime that satisfies (4). In other words, a pressured stance exists whenever positive contributions on behalf of regime $R$ are needed to induce the government to choose this outcome, when all of the opponents of $\mathrm{R}$ bid their maximum willingness to pay for the alternative. When this inequality fails, the proponents of the regime $R$ that satisfies (4) will refrain from 
offering any contributions and the government will choose $R$ nonetheless.

It is possible that both a pressured and an unpressured stance will exist for some parameter values. In the event, the two stances may select the same policy outcome. But this need not be the case. Whereas the unpressured stance always endorses the socially preferred regime, the pressured stance may select the regime that harms the average voter. This happens anytime the aggregate profit gain from $R$ relative to $\tilde{R}$ exceeds a times the social welfare loss.

In cases where pressured and unpressured stances both exist and support different policy positions, there may be compelling reasons to focus primarily on the pressured stance. In these circumstances, the unpressured stance does not survive as an equilibrium when we allow a limited degree of communication and coordination among the lobbies. In particular, we can introduce the notion of a coclition-proof equilibrium, as discussed by Bernheim et al. (1987). Under this refinement of the equilibrium concept, a Nash equilibrium is rejected if there exists a set of actions for some coalition of players that would increase (or not decrease) the payoff to each member of the coalition given the actions of non-members and that would not require any monitoring, because each proposed action constitutes a best response to the proposed or given actions of all others. The idea is that a member of such a coalition might be able to communicate with prospective partners so as to suggest the alternative plays and to point out that all would benefit under these plays. Seeing the entire list of proposed plays by coalition members, each would realize that there is no incentive for any to cheat, assuming that the others do as proposed.

The unpressured stance fails this test anytime it selects a regime different from the pressured stance. For suppose that (3) is satisfied for $\mathrm{R}$ and (4) is satisfied for $\tilde{\mathrm{R}}$. In the unpressured stance, all supporters of $R$ contribute nothing. An industry that is harmed by $R$ could propose a coalition comprising all such industries. It could propose that the members each contribute just enough so that the total contributions overcome 
the government's sensitivity to voter opposition. No member would be asked to contribute more than what it has to gain. Then, given the zero contributions of the nonmembers of this coalition, the government would be induced to choose $\tilde{R}$. Each member of the coalition would benefit. And each would see itself as pivotal and so would have no incentive to deviate, given the proposed actions of the others. Since we have assumed that (4) is satisfied for $\tilde{R}$, the collective gains of the members of the coalition are large enough to allow for the design of such a proposal. Evidently, the unpressured stance rests on the inability of opponents of the chosen regime to coordinate their political activity even to a minimal extent.

Bernheim and Whinston (1986) prove that all coalition-proof equilibria in menu auctions select an action from among the set of actions that maximizes the joint welfare of the principals and the agent, and also that any element in this set can be supported as a coalition-proof equilibrium. Here, the government acts as agent for the many interest groups and condition (4) expresses the requirement for joint welfare maximization. ${ }^{8}$ Since the regime that maximizes joint welfare always exists, we have proven

Result \&. A coalition-proof stance always exists. This stance supports regime $\mathrm{R}$ if and only if (4) is satisfied.

Results 2 and 3 imply immediately that all pressured stances are coalition proof.

This completes our discussion of the equilibrium political interactions in a single

\footnotetext{
8 Bernheim and Whinston (1986) also show that any action taken in a coalition-proof equilibrium can be supported by truthful strategies and that every equilibrium with truthful strategies is coalition proof. In our context, truthful strategies are those in which each lobby bids nothing for its less preferred regime, a lobby on the losing side offers for $\tilde{R}$ the full amount that it stands to lose from $R$, and a lobby on the winning side pays for $R$ at most what it stands to gain relative to $\tilde{R}$.
} 
country. To summarize, there always exists at least one unilateral stance. This stance may be pressured or unpressured. When a pressured stance exists, it always supports the (generically) unique regime that maximizes the joint welfare of lobbies and politicians. When an unpressured stance exists, it supports the regime favored by voters. When both exist, they may or may not endorse the same outcome. If they do not, then only the pressured stance will be coalition proof. In these situations, it will be possible for a coalition of lobbies to upset the unpressured stance by minimal coordination of their political acitivies.

\section{EQUILIBRIUM AGREEMENTS}

We turn now to the international negotiation. Our prohibition on exclusions leaves the two governments with little to negotiate about. In principle, they could discuss compensation payments that would be made from one treasury to the other under the terms of a potential agreements. Such compensation schemes do play a part in some regional trade agreements, such as in the European Community. But transfers still seem the exception rather than the rule (for example, they are not included in the terms of the proposed North American Free Trade Agreement), and even where they are used, they often are limited in scope. While we could include (limited or full) opportunities for compensation in our analysis of FTA's, to avoid a taxonomy we choose to focus on the case where no such opportunities are available.

In the event, an FTA without exemptions requires the unilateral support of both governments. If the lobbies in one country anticipate that the other government will seek an agreement, they will expect that their own country's political deliberations will determine the fate of the FTA. Then they will act exactly as described in our analysis 
of unilateral stances in section $3 .^{\circ}$ In a sub-game perfect Nash equilibrium, all expectations about the behavior of the other government are fulfilled. This justifies the following definition:

Definition: An FTA is an equilibrium agreement if and only if $\mathrm{R}=\mathrm{F}$ is a unilateral stance in both countries.

Our objective in this section is to characterize the economic and political conditions in the two countries under which an FTA can arise as an equilibrium outcome.

A main theme in our discussion will be the following: The political viability of an FTA typically requires sufficient "balance" in the potential trade between the parties to the agreement. To motivate the analysis in this section, it helps to begin with an extreme case. Suppose that all goods exported by country $A$ in the status quo ante are also exports of country $B$ and that country A has the higher MFN tariff in all of its import-competing sectors. Then country A would not export to country B at all in the event of an agreement. This means that none of the lobbies in $A$ would support the agreement. If most industries would experience enhanced protection, then welfare in $A$ would be likely to fall, in which case there could be no unilateral stance in $A$ in support of the FTA. On the other hand, if most industries would experience reduced protection, then the potential opposition to the agreement from the special interests would be great. The only chance for the agreement in this case of extreme imbalance in potential trade would be if the agreement happened to be welfare improving and the opposing interests failed to coordinate their lobbying activities or if they were unable to muster enough

9 If the Nash equilibrium entails a continuation of the status quo, then lobbies in at least one country must expect that the other will oppose the agreement at the international negotiation. These lobbies will contribute nothing to block the agreement, because they will believe its fate to be doomed in any case. This means that a pressured stance against an FTA will be observed in an international equilibrium in at most one country. 
opposition to block the accord. And even this last scenario would be unlikely, if the initial MFN tariffs also were the outgrowth of a political process. 10

In order to be more precise about what we mean by balance and also to see how industry conditions influence the political outcome, we turn to a special (but less extreme) case with particular functional forms. We suppose now that the households in both countries share identical utility functions wherein all of the non-numeraire goods enter symmetrically and each $u_{j}(\cdot)$ is quadratic. Then aggregate demand for any good $i$ in country $j$ has the linear form

$$
\mathrm{D}_{\mathrm{i}}^{\mathrm{j}}\left(\mathrm{q}_{\mathrm{i}}^{\mathrm{j}}\right)=\mathrm{D}-\mathrm{bq} \mathrm{q}_{\mathrm{i}}^{\mathrm{j}} \quad \text { for } i=1,2, \ldots, n \text { and } \mathrm{j}=\mathrm{A}, \mathrm{B} \text {. }
$$

Also, aggregate world supply of each of these goods is the same and the supply in each country is inelastic. Moreover, we assume that $\mathrm{X}_{\mathrm{i}}^{\mathrm{A}}=\theta \mathrm{X}$ and $\mathrm{X}_{\mathrm{i}}^{\mathrm{B}}=(1-\theta) \mathrm{X}$ in a fraction $s$ of the industries, while $\mathrm{X}_{\mathrm{i}}^{\mathrm{A}}=(1-\theta) \mathrm{X}$ and $\mathrm{X}_{\mathrm{i}}^{\mathrm{B}}=\theta \mathrm{X}$ in the remaining fraction $1-s$ of the industries. In other words, all industries are mirror images, with country A having the larger supply in some industries and country $B$ the larger supply in the others. Without further loss of generality we can take $\theta>1 / 2$ and $s \geq 1 / 2$. Then $s$ measures the extent of imbalance in the number of potential export industries, whereas $\theta$ measures the imbalance in output in any one sector.

The viability of an FTA also depends, of course, on the structure of the initial MFN tariffs. So far we have taken these as arbitrary. But it is reasonable to suppose that they too were an equilibrium outcome to a prior political battle. For the purposes of our illustrative example, we now assume that the MFN tariffs initially protecting the

10 We will see below that if the MFN tariffs are the result of a political process similar to the one assumed to precede the negotiation of the FTA, then the joint welfare of the government and the lobby must fall in any import-competing industry where a tariff rate is lowered. This means that no pressured stance could support an FTA if all industries were import competing and all experienced reduced protection under the FTA. 
import-competing industries in each country are those that would result from a lobbying game similar to the one described here, as derived in our 1994 paper. Assuming that both sets of politicians place the same weight $a$ on aggregate welfare in their objective functions, application of Proposition 1 in Grossman and Helpman (1994) gives

$$
\tau_{i}^{j}=1+\frac{X_{j}^{j}}{a b} \quad \text { for } j=A, B
$$

and for all sectors $i$ that have positive imports in the initial equilibrium.

In this example, different types of outcomes emerge depending on the configuration of parameter values. We will examine three different sets of parameter restrictions. While these possibilities do not exhaust the entire parameter space, they do illustrate all of the different considerations that may come into play. We begin with

Restriction 1: (D-b)/X > $1+\theta / \mathrm{a}$.

With this restriction on the parameters, all of the non-numeraire goods are imported in both countries in the initial equilibrium, when the MFN tariffs given in (6) apply. Country $A$ has the higher import tariff in the fraction $s$ of industries where its supply is $\theta \mathrm{X}$, while country $\mathrm{B}$ has the higher tariff in the remaining fraction $1 \rightarrow$ of industries. This is because the political processes are similar in the two countries, and the special interests in each country are willing to contribute more in their initial bids for MFN protection when they have more output at stake.

Under an FTA, each country would import from its partners all of those goods on which its MFN tariff is higher. This means that A would import a fraction $s$ of the nonnumeraire goods from B, and B would import the remaining fraction 1-s of these goods from A. Moreover, under Restriction 1, the output in the low-tariff country would not 
suffice to satisfy import demand in the bigh-tariff country at the latter country's preagreement domestic price. Therefore, recalling Table 1, all industries would experience enhanced protection under the proposed FTA. It is straightforward to calculate the contribution of sector $i$ to the change in aggregate welfare in each country using the formulas from Section 2.4. We find

$$
\Delta W_{i}^{j}=\left\{\begin{array}{ll}
-\frac{\theta(1-\theta) X^{2}}{a b} & \text { if } x_{i}^{j}=\theta x \\
\frac{\theta(1-\theta) X^{2}}{a b} & \text { if } x_{i}^{j}=(1-\theta) X
\end{array} \quad \text { for } j=A, B\right.
$$

Notice that what one country gains in aggregate welfare, the other loses.11

We can also calculate the profit changes that would result from the FTA. With all industries experiencing enhanced protection, the various import-competing interests in the high-tariff sectors do not suffer any profit loss. On the other hand, the factor owners in industries that would export under the agreement all gain. We have

$$
\Delta \Pi_{i}^{j}=\left\{\begin{array}{ll}
0 & \text { if } \quad x_{i}^{j}=\theta X \\
\frac{(2 \theta-1)(1-\theta) X^{2}}{a b} & \text { if } \quad x_{i}^{j}=(1-\theta) X
\end{array}, \quad \text { for } j=A, B\right.
$$

We are now ready to examine the unilateral stances. From (7) we see that an unpressured stance can favor an FTA in country A only if $s=1 / 2$; i.e., if the number of potential export industries is exactly the same in each country. If $s=1 / 2$, the FTA is welfare neutral, and the government in A could (marginally) support an agreement

"Joint social welfare in the two countries does not change, because outputs are fixed in each country and consumer prices do not change, so neither do demands. With a fixed allocation of resources in each country, only the distribution of the industry surplus can be affected by the FTA. 
without any lobbying on its behalf. But if $s>1 / 2$, the welfare loss from the fraction $s$ of high-tariff industries in country A would exceed the welfare gain from the fraction $1-s$ of low-tariff industries. Some political activity on the part of the beneficiaries would be necessary for the FTA to materialize.

What about the pressured stances? Using (7) and (8) we find that condition (4) indicates pressured support for an agreement in country $B$ for all $s \geq 1 / 2$, and that the government of country A will be induced to favor the accord if and only if

$$
s \leq \frac{1}{2}+\frac{\theta-1 / 2}{2 \theta-1+2 a \theta}<1 .
$$

The inequality in (9) will be satisfied for $s$ sufficiently close to one half. Then the potential profit gains to the owners of the fraction $1-s$ of the specific factors will be sufficiently large in the aggregate to outweigh the cost to the average voter. On the other hand, if $s$ is close to one, then the contributions by supporters of the agreement will not be sufficient to sway the government in the light of the prospective harm to the general public. For a given value of $s$, a pressured stance in $\mathrm{A}$ is more likely to support the FTA the smaller is the weight a that the government attaches to aggregate welfare, since welfare in A surely falls under the agreement. Finally, the political viability of a potential agreement increases with the extent of supply imbalance in a representative industry, because the potential profit gains for exporters grow more rapidly with $\theta$ than do the social welfare losses in the import sectors.

Our next parameter restriction is

Restriction 2. $1+(1-\theta) / \mathrm{a}>(\mathrm{D}-\mathrm{b}) / \mathrm{X}>\theta+\theta / \mathrm{a}$.

When this restriction holds, all non-numeraire goods again are imported by both 
countries in the pre-agreement equilibrium. But now, using the tariff formula (6), we find that the supply of output in the low-tariff country in each industry is enough to satisfy all demand by the other country at the low-tariff country's price. This means that all industries would experience reduced protection under the agreement.

Again we can calculate the contribution of sector $i$ to the change in aggregate welfare in each country. This will depend upon whether $i$ is a high-tariff or low-tariff sector. In the case of a high-tariff sector we find

$$
\Delta W_{i}^{j}=\frac{X^{2}}{a b}\left[(\theta-1)\left[\frac{D-b}{X}-\theta\right]+\frac{1}{2 a}\left(2 \theta^{2}-2 \theta+1\right)\right] \leqslant 0 \quad \text { for } X_{i}^{j}=\theta X
$$

The ambiguity here reflects the offsetting effects of trade creation and trade diversion. Meanwhile, the low-tariff sectors in each country become exporters under the agreement, and the contribution of these sectors to aggregate welfare necessarily rises. The applicable expression is 12

$$
\Delta W_{i}^{j}=\frac{X^{2}}{a b}(1-\theta)\left[\frac{D-b}{X}-\theta-\frac{1-\theta}{a}\right]>0 \text { for } X_{i}^{j}=(1-\theta) X
$$

Country A has a fraction $s$ of high-tariff sectors and a fraction 1-s of low-tariff sectors. Using the expressions in (10) and (11) we find that aggregate welfare may rise or fall under an FTA. If the potential export industries are evenly divided $(s=1 / 2)$, then aggregate welfare must rise. Then an unpressured stance favors an FTA in both countries as long as the total number of specific factors exceeds four. ${ }^{13}$ On the other

12 By restriction 2, $(D-b) / X>\theta+\theta / a$. Then, since $\theta>1 / 2$, the expression in square brackets in (11) must be positive.

13 When $s=1 / 2$, a times the aggregate welfare gain in each country equals $n(2 \theta-1) X^{2} / 4 a b$. Then using the formula for the profit loss of highly-protected producers (see (12) below), we find that condition (3) for an unpressured stance in favor of $F$ is 
hand, if $s=1$, aggregate welfare must rise in country $B$, but rises in A only if the expression in (10) is positive. Then even if the special interests that will be hurt by the FTA fail to coalesce into a (non-cooperative) coalition, the outcome of the negotiation remains in doubt.

In this case of reduced protection, the most politically powerful producers in each country (i.e., those that succeeded in securing high barriers in the initial political equilibrium) would be harmed by an agreement. And the other producers would not gain. The profit changes are given by

$$
\Delta \Pi_{\mathfrak{i}}^{j}=\left\{\begin{array}{ll}
-\frac{x^{2}}{a b} \theta(2 \theta-1) & \text { if } x_{i}^{j}=\theta x \\
0 & \text { if } x_{i}^{j}=(1-\theta) x
\end{array}, \text { for } j=A, B\right.
$$

Suppose that the industries are evenly divided between the countries $(s=1 / 2)$. In this case the aggregate profit loss in the $n / 2$ high-tariff industries must exceed $a$ times the aggregate welfare gain. So the pressured stance in each country rejects the FTA. As $s$ increases, industry opposition to the agreement eases in country $B$, but intensifies in country A. Moreover, as the number of import sectors in A rises above one half, the added pressure from industry to block the agreement outweighs any increased willingness on the part of the government to cater to the average voter. 14 It follows that

satisfied if and only if $\mathrm{n} \geq 4 \theta$. But since $\theta<1$, this must be satisfied for all $\mathrm{n}>4$.

14 That is, suppose we shift one sector from the list of potential exporters to that of potential importers. The welfare benefit of the FTA may rise or fall. But in any case, the political support for the agreement as measured by $\Delta \Pi^{A}+a \Delta W^{A}$ must decline. We calculate using (10), (11), and (12) that

$$
\mathrm{d}\left(\Delta \Pi^{\mathrm{A}}+\mathrm{a} \Delta \mathrm{W}^{\mathrm{A}}\right) / \mathrm{ds}=-\frac{\mathrm{X}^{2}}{\mathrm{ab}}\left[\theta^{2}-\frac{1}{2}+(1-\theta)\left[2 \mathrm{a}\left(\frac{\mathrm{D}-\mathrm{b}}{\mathrm{X}}-\theta\right)-1+\theta\right]\right] .
$$

This must be negative for parameters that obey restriction 2 . Thus, if (4) is satisfied for 
the pressured stance in A rejects the FTA not only when $s=1 / 2$, but for all values of $s \in[1 / 2,1]$. The international outcome must be a continuation of the status quo if the special interests in A induce a coalition-proof stance.

The final parameter restriction that we consider is

Restriction 9: $\theta>(\mathrm{D}-\mathrm{b}) / \mathrm{X}>(1-\theta)(1+1 / \mathrm{a})$

In this case the producers in each country with output $\theta \mathrm{X}$ export their product in the initial equilibrium. Since we rule out export subsidies, they receive only the international price for their goods. Meanwhile, the producers with output $(1-\theta) X$ cannot satisfy domestic demand at the tariff-inclusive domestic price, when the tariff is given by (6). These sectors are protected in the initial equilibrium. But it can be shown that all industries experience reduced protection under the FTA, so that international prices then would prevail in all sectors.

The export sectors again gain nothing from an FTA. But this time, these sectors also contribute nothing to the change in aggregate welfare, as no tariff revenue is collected on the imports that replace diverted sales. The factor owners in importcompeting sectors sacrifice profits under an agreement, while the contribution of these sectors to aggregate welfare expands. We must as usual evaluate the sum of $\Delta \Pi_{i}^{j}$ and $a \Delta W_{i}^{j}$, but now the sum need only be taken over the import-competing industries in country $j$. In each such industry tariff revenue falls due to trade diversion, and a politically-motivated tariff is removed. Since the MFN tariffs in (6) were themselves set to maximize a political objective function, their elimination must reduce the joint welfare of the lobby and the government. 15 It follows that the pressured stance rejects

$\mathrm{R}=\mathrm{N}$ when $s=1 / 2$, it must also be satisfied for $\mathrm{R}=\mathrm{N}$ when $s>1 / 2$.

is It is possible, of course, to calculate $\Delta \Pi_{i}^{j}+a \Delta W_{i}^{j}$ for a typical import-competing 
the agreement in both countries.

Let us summarize what we have learned from this example. First, an FTA is more likely to be supportable as an equilibrium outcome when $s$ is close to one half. This is the sense in which potential trade between the countries must be balanced: There must be a sufficient number of potential exporters in each country who will lobby for the agreement, or a sufficient number of sectors with assured welfare gains to offset the potential losses from trade diversion. A second and more pessimistic conclusion may be warranted. Recall that an FTA can emerge as a coalition-proof equilibrium outcome for some parameters satisfying restriction 1 , but not for any that satisfy restriction 2 or 3 . In the first of these cases, all industries experience enhanced protection. Then the export industries are willing to contribute heavily in support of the agreement. In the second and third cases, reduced protection prevails, and then import-competing industries are most vehement (and forthcoming) in their opposition. But enhanced protection generally means joint welfare losses for the two countries, while reduced protection generates joint welfare gains. So, an FTA is most likely to be politically viable exactly when it would be socially harmful. 18

sector. The expression for $\Delta \Pi_{i}^{j}$ is the same as that given in the top line of (12), while the expression for $\Delta W_{i}^{j}$ is the same as that given in (10). Then we can verify that $\Delta \Pi_{i}^{j}$ $+\mathrm{a} \Delta \mathrm{W}_{\mathrm{i}}^{\mathrm{j}}<0$ for all parameters that obey restriction 3 .

18 Hirschman (1981) made a similar point in his prescient discussion of the dynamics of the European Community. In our model the association between social inefficiency and political viability is stark, because exporters can gain from an agreement only when domestic prices in the partner country rise. This need not be the case in more general models. For example, if products were differentiated by country of origin, the exporters of a good could gain even as tariff-inclusive prices fell in the importing market. The same would be true if high transport costs segmented countries $A$ and $B$ from the rest of the world prior to any agreement. But there is one point here that is quite general. When discriminatory tariffs give rise to trade diversion, the gains to exporters in one country come at the expense of the general taxpayer in the other. To the extent that industry interests are better represented in the political process than taxpayer interests, trade divergence will enhance political viability while reducing total welfare. 


\section{INDUSTRY EXCLUSIONS}

Governments that are considering a free trade agreement have some ability to make a pact palatable to opposing interests, or at least to mitigate their opposition. They can do so by providing long periods of adjustment to some sectors and by excluding others from the agreement entirely. However, the governments inevitably must clash on the issue of exceptions, because each seeks to preserve protection for some of its politically powerful industries, while trying to gain market access for all of its potential exporters. An equilibrium agreement is one that reflects the political pressures on each government and also the give and take of the bargaining process.

In this section, we examine how industry exclusions might make an FTA politically viable that otherwise would not be. We also investigate the determinants of the identity and number of excluded sectors. We use "exclusions" here to represent not only the granting of permanent exemptions from an agreement, but also as a metaphor for long phasein periods. The number of such exclusions should not be so large as to violate the GATT stipulation that an FTA must liberalize "substantially all trade."

\subsection{Unilateral Stances}

We begin as before by focusing on the political interactions in a single country. We investigate what type of agreement (if any) a government would choose in response to domestic political pressures, assuming that it could dictate the terms of the agreement to its potential partner. Of course, an equilibrium agreement need not look anything like the unilateral stance; but it helps to understand the political process in one country before turning to the two-country bargaining problem.

The lobbies' contribution schedules now must reflect the various positions that its government might take. A government can choose to reject an agreement entirely, it 
can pursue an agreement calling for the exclusion of certain sectors, or it can seek an agreement with completely free bilateral trade. In principle, the lobbies might link their contributions to the identities of all entries on the list of excluded sectors. However, in our economy, the owners of a specific factor care only about the fate of their own industry. An industry facing the prospect of increased competition from partner imports will prefer that its protection be preserved for as long as possible (here, indefinitely), while an industry that hopes to find a new or expanded export market in the partner country will not want to see its products among those excluded from the agreement. We can assume, therefore, without loss of generality that the special interests distinguish their contribution offers only among outcomes that affect their profits. Each lobby $i$ specifies exactly three numbers, denoted $\mathrm{C}_{\mathrm{iN}}, \mathrm{C}_{\mathrm{iE}}$, and $\mathrm{C}_{\mathrm{iI}}$, that represent its campaign gift in the event that the government rejects the FTA, in the event that it concludes an FTA but with industry $i$ excluded from the agreement, and in the event that it concludes an FTA with industry $i$ included in the agreement, respectively. ${ }^{17}$ Excluded sectors retain their MFN tariffs once any FTA is enacted.

We can define a unilateral stance in much the same way as we did in Section 3. In particular, the unilateral stance supports some regime; either the government rejects the agreement entirely $(R=N)$, or it opts for an agreement $(R=F)$ with a particular set of excluded sectors. In the latter case, the number of excluded sectors may be zero and must not exceed the exogenous limit $e$ that we use to represent the constraints imposed by the GATT. In an equilibrium stance, the government achieves greater political welfare $G$ than it could under any alternative regime satisfying GATT rules. And no lobby is able to redesign its offer triplet, given the offers of the other lobbies and

17 In a world with differentiated products and two-way trade, we would need to allow for the possibility that an agreement removes one country's barrier to imports of good $i$, but not the other's. Here, trade in any one good is unidirectional, with imports going from the low-tariff to the high-tariff country. In this context, an industry exclusion means that the high-tariff country retains its barrier to imports from its FTA partner. 
the anticipated optimization by the politicians, in such a way as to increase its profits net of contributions.

In describing the unilateral stances that can emerge as equilibrium government responses to political pressures, it will prove convenient to refer to the politically optimal set of exclusions, $\mathrm{E}(\mathrm{e})$. We define this set as follows:

Definition: The set of politically optimal exclusions $\mathrm{E}(\mathrm{e})$ is the largest set of sectors such that (i) $\mathrm{i} \in \mathrm{E}(\mathrm{e})$ implies $\Delta \Pi_{\mathrm{i}}+a \Delta \mathrm{W}_{\mathrm{i}} \leq \min \left[\min _{\mathrm{j} \notin \mathrm{E}(\mathrm{e})}\left(\Delta \Pi_{\mathrm{j}}+a \Delta \mathrm{W}_{\mathrm{j}}\right), 0\right] ;$ and (ii) $\# E(e) \leq e$.

The first part of the definition states that, for any industry in the set $E(e)$, the joint gain to the government and the factor owners from liberalizing bilateral trade in good $;$ must be non-positive and in fact more negative than for any sector among those not in the set $E(e)$. The second part of the definition says that the number of elements of the set $E(e)$ - denoted \#E(e) - should not exceed the exogenous limit on the number of allowable exclusions.

Our first result concerns coalition-proof stances. It says

Result 4: There exists a coalition-proof stance with $\mathrm{R}=\mathrm{F}$ if and only if

$$
\underset{i \in E(e)}{\sum}\left(\Pi_{i N}+a W_{i N}\right)+\sum_{i \in E(e)}^{\sum}\left(\Pi_{i F}+a W_{i F}\right) \geq \sum_{i}\left(\Pi_{i N}+a W_{i N}\right)
$$

In this stance, the sectors $i \in E(e)$ are excluded from the agreement.

The left-hand side of (13) gives the joint welfare of all lobbies and the government under an FTA with excluded sectors $E(e)$, while the right-hand side gives the joint welfare of 
these parties in the status quo. The result follows from Theorem 3 of Bernheim and Whinston (1986), which states that every coalition-proof equilibrium in a menu auction selects an action from among those that maximize the joint welfare of the principals and the agent. 18 In the coalition-proof unilateral stance, the constraint on the number of exclusions binds if and only if there are at least $e$ industries that would lose more in profits by being included in the agreement than a times what the average voter would gain from having them included. The excluded industries are those that are most politically sensitive, in the sense that their inclusion imposes the greatest cost to specific factor owners and politicians taken together.

The coalition-proof stance can be supported by "truthful offers" in which each lobby bids the same amount for an exclusion as for an outright rejection of the agreement $\left(C_{i E}=C_{i N} \geq 0\right.$ for all $\left.i\right)$, all industries $j E(e)$ bid for an exclusion exactly what they stand to lose (if anything) by being included in the agreement, and all industries $i \in E(e)$ bid for an exclusion at most what they stand to save by having their trade barriers preserved, and exactly what is needed to ensure that they are among those excluded. This stance may be pressured, in the sense that at least some of the industries that stand to gain from the FTA contribute actively on its behalf (i.e., $C_{i I}>0$ for some i). The joint contributions of these (export) industries then are just sufficient to overcome the political resistance to the agreement.

Inequality (13) may hold even when inequality (4) fails for $R=F$. That is, the coalition-proof stance may endorse an FTA with exclusions in cases where it would reject the agreement in the absence of exclusions. The exclusions allow the government to avoid the biggest political costs associated with an FTA, and the net political gain may be positive once these particularly exposed sectors are sheltered from the

18 Note that $E(e)$ maximizes $\sum_{i \in \tilde{E}}\left(\Pi_{i N}+a W_{i N}\right)+\sum_{i \notin \tilde{E}}\left(\Pi_{i F}+a W_{i F}\right)$ among all sets $\tilde{E}$ that have \# $\tilde{\mathrm{E}} \leq \mathrm{e}$. 
agreement.

When inequality (13) does fail, a coalition of industries can block any stance in support of an FTA by promising sufficient contributions in the event that the status quo is preserved. Moreover, the contributions that block a proposed FTA require no monitoring (they are best responses) and leave each coalition member at least as well off as under the agreement. However, as before, the interests that oppose the FTA may fail to achieve the required degree of coordination, if their opportunities for communication are limited or if there are very many of them. In the event, the politics may give rise to a unilateral stance in support of an FTA, even though the interests that stand to benefit from the agreement contribute nothing to further its cause. We will refer to such a stance with all $\mathrm{C}_{\mathrm{iI}}=0$ as unpressured. The next result gives the necessary and sufficient conditions for the existence of such a stance. ${ }^{10}$

Result 5: There exists an unpressured stance with $R=F$ if and only if

$$
\underset{i \in E(e)}{\sum} a W_{i N}+\underset{i \notin E(e)}{\Sigma} a W_{i F}+C \geq \underset{i}{\sum a W_{i N}}+\max \left[0, \underset{i \notin E(e)}{\max }\left(\Pi_{i N}-\Pi_{i F}\right)\right]
$$

for a particular, non-negative $C \leq \underset{i \in E(e)}{\sum}\left(\Pi_{i N}-\Pi_{i F}\right)$. In this stance, the sectors $i \in E(e)$ are excluded from the agreement.

The appendix provides a proof of this result and also gives the exact expression for the constant $\mathrm{C}$. Intuitively, $\mathrm{C}$ represents the total amount of contributions by lobbies that are excluded from the agreement, when each such lobby gives the minimum amount that ensures it a place on the list of exclusions (given the equilibrium bids of the other

19 It is unpressured in the sense that the government's decision to pursue the agreement elicits no contributions from beneficiaries. The government may, however, collect contributions from some or all of the industries that are granted exclusions. 
lobbies). No lobby would contribute more than its prospective profit loss in order to secure an exclusion, which explains the upper bound on C. And some industries may need to contribute less than the total amount of the profits they stand to lose, if for example, the inclusion of these industries would contribute to a decline in voter welfare and so the government would wish to exclude them even without any pressure. In view of this interpretation of $C$, Result 5 is quite analogous to Result 1 . The stance in favor of $\mathrm{F}$ can exist because the opponents of the agreement may contribute little or nothing toward their common cause. Then it may be that no single lobby among those not excluded from the agreement has enough at stake to warrant its acting unilaterally to reverse the stance.

From Results 4 and 5 we see that all unilateral stances in support of an FTA share the same set of (politically optimal) exclusions. It is easy to see why. Suppose, to the contrary, that there were a unilateral stance in which some sector $i \in E(e)$ were not exempted and that perhaps some $\mathrm{j} E(e)$ were excluded in its place. First, if there were no such $j$, then $i$ would be willing to bid up to $\Pi_{\mathrm{iN}}-\Pi_{\mathrm{iF}}$ in order to secure an exclusion. The government would add $i$ to the exclusion list if the contribution were large enough to compensate for the political cost, $a\left(W_{i F}-W_{i N}\right)$. But according to the definition of $\mathrm{E}(\mathrm{e})$, we must have $\Pi_{\mathrm{iN}}-\Pi_{\mathrm{iF}} \geq \mathrm{a}\left(\mathrm{W}_{\mathrm{iF}}-\mathrm{W}_{\mathrm{iN}}\right)$, because $\Delta \Pi_{\mathrm{i}}+\mathrm{a} \Delta \mathrm{W}_{\mathrm{i}} \leq 0$. Second, if there were some $j$ in the place of $i$ on the list of exemptions, that industry would have bid at most $\Pi_{j N}-\Pi_{j F}$ for its place on the list. Again, the definition of $E(e)$ ensures that $i$ could bid something less than its potential profit gain but enough to induce the government to exclude $i$ rather than $j$. The competition among lobbies for places on the exclusion list ensures that this list will be "politically efficient" from the point of view of the special interests and the politicians. The only time that unexploited gains may remain for these groups is when the adversely affected industries fail to coordinate their political actions so as to block entirely an FTA that is not in their collective interest. 


\subsection{Exclusions that Save an FTA}

In this section we illustrate by means of an example that the ability to grant industry exclusions can save an FTA that would not be viable as an equilibrium outcome in the absence of such exclusions. Here we will show only that, for our example, there exist agreements with exclusions that are preferred by both governments (considering the political pressures they face) to the status quo. We defer until next section a discussion of the bargaining process.

The example is one that we have considered before. There are identical linear demands in countries $\mathrm{A}$ and $\mathrm{B}$ and fixed and equal outputs in all non-numeraire sectors. In a fraction $s>1 / 2$ of these sectors country $A$ has output $\theta \mathrm{X}$ and country $B$ has output $(1-\theta) X$, with $\theta>1 / 2$. The outputs are reversed in the remaining sectors. Finally, we impose the previously described restriction 1 , so that all sectors would experience enhanced protection under an FTA. Recall that, while country B must favor the agreement in this case, all equilibrium stances in country $A$ reject the FTA when the imbalance in the number of potential export industries is relatively large.

Let us consider a proposal to exclude from the FTA a number $\mathrm{e}^{\mathrm{A}}$ of the sectors in which $A$ would import from $B$ under an agreement without exemptions, and a number $e^{B}$ of the sectors in which $B$ would import from $A, e^{A}+e^{B} \leq e$. How would the politically motivated governments view such a proposal as compared with the outcome of no FTA? We know that, if it came to a binary choice between $R=N$ and $R=F$ with the proposed exclusions, the political process would choose the latter as a coalitionproof stance if and only if the joint welfare of the lobbies and politicians would be higher in that regime. It is straightforward to check, using the expressions in (7) and (8), whether that is indeed the case for countries $A$ and $B$.

Under the proposed agreement, sn $-e^{A}$ sectors would contribute to a loss of aggregate welfare in country $A$; the size of the typical loss is given in the top row of (7). 
Meanwhile, $(1-5) n-e^{B}$ sectors would contribute a welfare gain of equal magnitude. These latter sectors would also generate a profit gain for specific factor owners of the amount given in the second row of (8). The remaining $e^{A}+e^{B}$ sectors would be excluded from the FTA and so would contribute neither gains nor losses. We calculate $a \Delta W^{A}+\Sigma_{i} \Delta \Pi_{i}^{A}$ for the proposed FTA, and find it to be positive if and only if

$$
\mathrm{s} \leq \frac{1}{2}+\frac{\theta-1 / 2}{2 \theta-1+2 \mathrm{a} \theta}+\frac{\mathrm{a} \theta \mathrm{e}^{\mathrm{A}}-(2 \theta-1+\mathrm{a} \theta) \mathrm{e}^{\mathrm{B}}}{\mathrm{n}(2 \theta-1+2 \mathrm{a} \theta)} .
$$

Suppose that $e^{A}>(2 \theta-1+a \theta) e^{B} / a \theta$. Then, comparing (15) with (9), we see that by allowing exclusions we expand the range of values of $s$ for which the FTA emerges as a coalition-proof stance in $A$. At the same time, if $e^{A}<\left[e^{B} \theta+(2 s-1) n a \theta+\right.$ $\operatorname{sn}(2 \theta-1)] /(2 \theta-1+a \theta)$, then the FTA remains the coalition-proof stance in country B. So clearly there are values of $s$ for which the FTA without exclusions would be rejected by country A, but where it would be possible to design an FTA with exclusions that would be politically viable in both countries. Note in particular that if $2 s-1<e / n$, the FTA with $e^{A}=(2 s-1) n$ and $e^{B}=0$ satisfies GATT rules and politically dominates the status quo ante. Under such an agreement both countries have an equal number of included import sectors, aggregate welfare in each country is the same as with no FTA, while profit gains are realized by some industries in each country.

We have identified cases where an FTA without exclusions would fail politically, but where some agreements with exclusions would be preferred to the status quo by politically-motivated governments in each country. In these cases, the introduction of a potential for exclusions will save the FTA, provided only that the governments engage in an efficient bargaining process. Our next task is to introduce an explicit bargaining mechanism and then ask what values of $\mathrm{e}^{\mathrm{A}}$ and $\mathrm{e}^{\mathrm{B}}$ will emerge from the negotiation. 


\subsection{Bargaining Over Industry Exclusions}

In the example we have been examining the government of country $A$ will want $e^{A}$ to be as large as possible and $\mathrm{e}^{\mathrm{B}}$ as small as possible; each exclusion of an industry in which A would otherwise import from B averts a potential welfare loss, while each exclusion of an industry in which A would otherwise export to B costs the country both a social gain and a source of new profits for the industry. Of course, the government of country B has exactly the opposite preferences. It sees potential political gains from excluding goods that would be imported from $A$ and by including those that would be exported to $A$.

We will study the inter-governmental negotiation in two stages. First we will simply assume that the two governments engage in an efficient bargaining process and thereby achieve an agreement with the property that neither could gain politically except at the expense of the other. Many but not all bargaining procedures lead to such an efficient outcome. After we explore the Pareto frontier of the two government's welfare, we will introduce a particular bargaining procedure and show how it pins down the precise terms of the free trade agreement.

We retain the linear example and restriction 1. We suppose also that inequality (9) is violated, so that the equilibrium stance in country A would favor the status quo over an FTA without exclusions. Clearly, country B will need to grant some exclusions to prospective import-competing industries in country $\mathrm{A}$, or else the government of $\mathrm{A}$ will refuse to enter into an agreement. In what follows we assume that the lobbies understand and forecast the bargaining procedure at the time that they make their offers, and also that they follow truthful strategies. In the present context this means that $C_{i E}^{j}=C_{i N}^{j}$ for all $i$ and $j=A, B$, since an industry's profits are the same when it is excluded from an agreement as when there is no agreement at all.

The first point to notice is that no negotiated agreement will grant a positive number of exclusions to prospective import-competing industries in country $B$. That is, 
$e^{B}=0$ for all points on the Pareto frontier. To see this, suppose the opposite were true. Consider a pact calling for $e^{A}>0$ and $e^{B}>0$, and compare it to another with one less exemption for each country. Aggregate welfare is the same for each country under the alternative proposals, because each export sector generates a welfare gain that matches the loss associated with an import sector (see (7)). Since all sectors experience enhanced protection in our example, no specific factor owners suffer any profit loss from being included in the agreement. So none would bid positively for an exemption. On the other hand, the prospective exporters do gain from the liberalization of bilateral trade, and so they are willing to pay in order to avoid the exclusion of their sector. By reducing both $e^{A}$ and $e^{B}$ by one, the governments generate no voter hostility, but each collects one more contribution from a potential exporter.

Now suppose that the lobbies in both countries expect $e^{A}>0$ and $e^{B}=0$ under any FTA that may materialize. Consider first the political game in country A. The lobbies representing high-tariff industries are indifferent to the agreement, because industry profits do not fall in the case of enhanced protection. Therefore, all these lobbies bid nothing to block the FTA, nothing to secure an exemption for their industry, and of course nothing to further the cause of the FTA; i.e., $C_{i E}^{A}=C_{i N}^{A}=C_{i I}^{A}=0$ for all $i$ such that $\mathrm{X}_{\mathrm{i}}^{\mathrm{A}}=\theta \mathrm{X}$. On the other hand, the lobbies representing potential export industries are keen to see the FTA go through and in particular to ensure that their sector is included in any agreement. These lobbies set $C_{i E}^{A}=C_{i N}^{A}=0$, but $C_{i I}^{A}>0$. They know that their government will accede to an agreement if and only if

$$
\Sigma_{i} C_{i I}^{A} \geq\left[(2 s-1) n-e^{A}\right] \frac{\theta(1-\theta) X^{2}}{b}
$$

The left-hand side of (16) represents, of course, the total contributions in support of the agreement, while the right-hand side is a times the social cost of an FTA with $e^{A}$ of $A^{\prime}$ 's 
import-competing sectors excluded.20 All lobbies contribute zero if the right-hand side of (16) is negative; i.e., if the FTA with exclusions would raise national welfare. Otherwise, if the lobbies jointly contribute enough to make the FTA lly, they will each reduce their contribution to the point where (16) holds as an equality. It remains to check only that these lobbies are willing to make sufficient contributions; i.e., that each stands to gain from the agreement at least what it is expected to pay. Each industry with $\mathrm{X}_{\mathrm{i}}^{\mathrm{A}}=(1-\theta) \mathrm{X}$ earns extra profits of $(2 \theta-1)(1-\theta) \mathrm{X}^{2} / \mathrm{ab}$ under an FTA (see (8)). So collectively their gains will be large enough to justify the requisite financial support if and only if $e^{A} \geq e_{\min }^{A}$, where

$$
\mathrm{e}_{\min }^{\mathrm{A}}=(2 \mathrm{~s}-1) \mathrm{n}-\frac{(1-\mathrm{s}) \mathrm{n}(2 \theta-1)}{\mathrm{a} \theta}
$$

If $e^{A} \geq e_{\min }^{A}$, there always exists at least one combination of contributions with the property that each potential export industry contributes at most $\Pi_{i F}^{A}-\Pi_{i N}^{A}$ and each one making a positive contribution is pivotal to the agreement. These contributions support a coalition-proof stance in favor of the agreement, as no lobby or group of lobbies has any incentive to deviate.

Now let us look at country B. There too the interest groups representing prospective import-competing industries make zero contributions in all contingencies. These lobbies know that their government does not intend to exclude any of B's import sectors and, in any event, they are not harmed by the competition in the case of enhanced protection. Contributions come only from the potential export interests, each one of whom seeks to avoid having its product among those excluded from the agreement. Competition among the (symmetric) export lobbies drives their

20 There are $(1-8) n$ industries with $X_{i}^{A}=(1-\theta) X$ and sn $-e^{A}$ included industries with $\mathrm{X}_{\mathrm{i}}^{\mathrm{A}}=\theta \mathrm{X}$. The expression for the welfare effect follows from (7). 
contributions to the maximum willingness to pay; i.e., $\mathrm{C}_{\mathrm{i} I}^{\mathrm{B}}=\Delta \Pi_{\mathrm{i}}^{\mathrm{B}}=$ $(2 \theta-1)(1-\theta) \mathrm{X}^{2} / \mathrm{ab}$ for all $i$ such that $\mathrm{X}_{\mathrm{i}}^{\mathrm{B}}=(1-\theta) \mathrm{X}$. Then the government of country $\mathrm{B}$ is amenable to an agreement if and only if

$$
\left(\operatorname{sn}-e^{A}\right) \frac{(2 \theta-1)(1-\theta) X^{2}}{a b}+\left(2 s n-n-e^{A}\right) \frac{\theta(1-\theta) X^{2}}{b} \geq 0
$$

The two terms on the left-hand side of (18) are the total contributions collected from the $\mathrm{sn}-\mathrm{e}^{\mathrm{A}}$ export sectors that are not excluded from the agreement and $a$ times the net welfare gain. Rearranging (18), we find that for an FTA to be politically viable in country $B$, the number of exclusions must not exceed $\mathrm{e}_{\max }^{\mathrm{A}}$, where

$$
\mathrm{e}_{\max }^{\mathrm{A}}=(2 s-1) \mathrm{n}+\frac{(1-s) \mathrm{n}(2 \theta-1)}{\mathrm{a} \theta+2 \theta-1}
$$

We are now ready to construct the Pareto frontier for the governments engaged in the trade discussions. In Figure 2, the axes measure the political welfare of the two governments. The point $N$ represents the values attained by $G^{A}$ and $G^{B}$ if no agreement is reached. Since neither government receives any contributions to block the agreement, this point has $G^{A}=a W^{A}$ and $G^{B}=a W^{B}$. Next we plot the utility levels achieved by the politicians under an FTA with different numbers of exclusions, $e^{A}$. For $e^{A}<e_{\min }^{A}$, the government of $A$ rejects the agreement in spite of the bids made on its behalf, and so the outcome remains at $N$. Now consider a proposal calling for slightly more than $\mathrm{e}_{\mathrm{min}}^{\mathrm{A}}$ exclusions. If lobbies in $\mathrm{A}$ anticipate this outcome, their contributions would be such as to make (16) hold as an equality. That is, the government would be left just indifferent between adopting the agreement and rejecting it. On the other hand, the government of country $B$ would achieve higher utility than at $N$, both because aggregate welfare there would be higher under the FTA and because it would collect 
contributions from its export lobbies seeking to avoid exclusion from the agreement. The left-hand side of (18) gives the gain to the government of country B from an FTA with $e^{A}$ exclusions, relative to the outcome at point $N$. The different values of $e^{A} \epsilon$ $\left[e_{\min }^{A},(2 s-1) n\right]$ trace out the different points along the segment $A B$ in the figure.

An FTA with $e^{A}=(2 s-1) n$ exclusions leaves aggregate welfare unchanged in country $A$, and so the lobbies there need not contribute anything to induce their government to accept such an agreement. The government of A still attains the same level of political welfare as when it rejects the agreement. But for $e^{A}>(2 s-1) n$, aggregate welfare in A is higher with the FTA than without it, and so the government's political welfare rises above the level at $N$, even though all campaign contributions in $A$ are zero (see (16)). Provided that $e^{A}<e_{\max }^{A}$, the government of $B$ also achieves higher political welfare than at $N$. The points along $B C$ in the figure correspond to numbers of exclusions in the range $\left[(2 s-1) n, e_{\max }^{A}\right]$. Finally, for $e^{A}>e_{\max }^{A}$, the government of $B$ rejects the agreement, and political outcome again is at $\mathrm{N}$. Thus, $\mathrm{ABC}$ represents the Pareto frontier for the two negotiating parties, and an efficient agreement leads to a number of exclusions between $\mathrm{e}_{\min }^{\mathrm{A}}$ and $\mathrm{e}_{\max }^{\mathrm{A}}$.

At last we are ready to illustrate how a particular bargaining procedure could be used to pin down the terms of the agreement. Suppose that the governments make alternating offers. ${ }^{21}$ Each government in its turn names a number of exclusions, $e^{A}$. If the other accepts the offer, the bargaining ends. But if the other rejects the offer, the negotiations break down with some exogenous probability. If they do not break down, the second government gets a chance to make a counter-offer. The procedure continues until an agreement is reached, or until the negotiations collapse. If the negotiations collapse, the status quo situation continues indefinitely.

It is clear that, with this procedure, the equilibrium outcome must occur

21 This is a modified version of the Rubinstein (1982) model, as described by Binmore et al. (1986) and Sutton (1986). 
somewhere along $\mathrm{BC}$ in Figure 2. The government of $\mathrm{A}$ would never accept any proposal offering fewer than $(2 s-1) n$, because lobbies anticipating such an outcome would have offered contributions that just leave the politicians indifferent between accepting the proposal and allowing the talks to end. In the event, the government of $\mathrm{A}$ would always choose to make a counteroffer, even at the risk of a breakdown in the talks. In our example, it is the country with the larger number of high-tariff industries that realizes welfare gains from the equilibrium FTA, while the other country's government trades off these gains for the political support it can amass from its eager potential exporters. ${ }^{22}$

The exact point of the equilibrium can be found by the method described in Grossman and Helpman (1993). In particular, the government making the first offer chooses one that leaves the other just indifferent between accepting and rejecting, in view of the positive probability of breakdown in the event of rejection but also the opportunity that rejection affords the other to design a more favorable counterproposal. The second government's counteroffer has the similar property that it leaves the first indifferent between accepting and rejecting. From these two equations we can determine the offer and counteroffer, which depend on the two governments' discount rates and their welfare under the status quo. Each government obtains an agreement more favorable to itself the lower is its discount rate relative to that of its opposite, and the higher is its country's aggregate welfare in the status quo ante.

\section{CONCLUSIONS}

We have examined the conditions under which a free trade agreement might

22 We note that, in our example, all potential agreements leave aggregate world welfare at the same level as without the FTA. Therefore, at most one country can benefit in welfare terms from any agreement. In other circumstances the equilibrium outcome might entail gains (or losses) for the average voter in both countries. 
emerge as an equilibrium outcome of a negotiation between politically-minded governments. The governments, we imagine, respond to political pressures from industry special interests, but also pay some heed to the plight of the average voter.

If an FTA must completely liberalize trade among the partner countries, then a particular government might endorse the agreement in two types of situations. The first arises when the agreement would generate substantial welfare gains for the average voter and adversely affected interest groups fail to achieve even minimal coordination in their efforts to block the accord. The second arises when the agreement would create profit gains for potential exporters to the partner country in excess of the losses that would be suffered by import-competing industries plus the political cost of any welfare harm that the agreement might inflict on the average voter.

A free trade agreement requires the assent of both governments. We have found that this outcome is most likely when there is relative balance in the potential trade between the partner countries and when the agreement affords enhanced protection rather than reduced protection to most sectors. With enhanced protection, an exporting industry captures the benefits of the high domestic prices in the partner country. With reduced protection, an import-competing industry sees its domestic price fall as a result of the duty-free imports from the partner. Whereas reduced protection may involve some trade creation, enhanced protection gives rise only to trade diversion. Thus, the conditions that enhance the viability of a potential agreement also raise the likelihood that the agreement would reduce aggregate social welfare.

If some industries can be excluded from an FTA, or can at least be granted long periods of adjustment, then the political prospects for an agreement improve. Each government would wish to exclude from an agreement those sectors whose inclusion would impose on it the greatest political costs. Political costs reflect either the fierce opposition of the import-competing interests or the harm that would be suffered by the average voter in the face of inefficient trade diversion. By excluding some sensitive 
sectors, a government may be able to diffuse the opposition to an FTA. In a bargaining situation, exclusions will tend to be concentrated in the country that otherwise would block the accord.

Our formal analysis of bargaining over industry exclusions focused on a case with only two types of industries in each country. Industries were categorized either as potential exporters or potential import-competitors, with symmetry within each of these groups. It is straightforward to extend the analysis to allow for more asymmetry. Then efficient bargaining would cause exclusions to be granted on the basis of comparative political advantage; that is, industries would be ranked on the basis of the political cost from inclusion to the government of the import-competing country in relation to the political benefit to the government of the exporting country.

We conducted all of our analysis under the restrictive (but somewhat realistic) assumption that governments cannot offer direct, treasury-to-treasury, transfer payments as compensation for any political costs associated with an agreement. It would be a simple matter to redo our analysis for the case where such transfers are feasible. The more interesting and difficult question in the political economy of international relations concerns the reasons why compensation payments have played such a limited role in most trade negotiations. 


\section{REFERENCES}

Bernheim, B. Douglas, Peleg, Bezalel, and Whinston, Michael D. (1987) "CoalitionProof Nash Equilibria I: Concepts," Journal of Economic Theory, 12, 1-12.

Bernheim, B. Douglas and Whinston, Michael D. (1986) "Menu Auctions, Resource Allocation, and Economic Influence," Quarterly Journal of Economics, 101, 1-31.

Binmore, Ken, Rubinstein, Ariel, and Wolinksy, Asher (1986) "The Nash Bargaining Solution in Economic Modelling," Rand Journal of Economics, 17, 176-188.

Grossman, Gene M. and Helpman, Elhanan (1993) "Trade Wars and Trade Talks," Working Paper No. 4280, National Bureau of Economic Research.

Grossman, Gene M. and Helpman, Elhanan (1994) "Protection for Sale," American Economic Review, forthcoming.

Hirschman, Albert O. (1981), Essays in Trespassing: Economics to Politics and Beyond, Cambridge: Cambridge University Press.

Krueger, Anne O. (1993) "Free Trade Agreements as Protectionist Devices: Rules of Origin," Working Paper No. 4352, National Bureau of Economic Research.

Olsen, Mancur. (1965) The Logic of Collective Action, Cambridge MA: Harvard University Press.

Richardson, Martin (1992) "Some Implications of Internal Trade in a Free Trade Area," Working Paper No. 92-01, Department of Economics, Georgetown University.

Rabinstein, Ariel (1982) "Perfect Equilibrium in a Bargaining Model," Econometrica, 50, 97-109.

Sotton, John (1986) "Noncooperative Bargaining Theory: An Introduction," Review of Economic Studies, 59, 709-724. 


\section{Appendix}

\section{Proof of Result 5}

Let the $\mathrm{C}$ referred to in result 5 be given by

$$
C=\sum_{i \in E(e)} \max \left[0, a\left(W_{i F}-W_{i N}\right)+J\right]
$$

where $J=\max _{j \notin E(e)}\left[\max \left(0, \Pi_{j N}-\Pi_{j F}+a W_{j N}-a W_{j F}\right)\right]$

\section{Sufficiency}

We establish first that an unpressured stance in support of an FTA exists under the stated conditions, with the set of excluded sectors $E(e)$. Let $C_{i N}=C_{i I}=0$ for all $i$, $C_{i E}=\max \left[0, a\left(W_{i F}-W_{i N}\right)+J\right]$ for $i \epsilon E(e)$, and $C_{i E}=\max \left(0, \Pi_{i N}-\Pi_{i F}\right)$ for if $E(e)$. Then $C=\sum_{i \in E(e)} C_{i E}$. It follows from (14) that with these contributions the government prefers $F$ with the excluded sectors $E(e)$ to $N$, and also to any FTA with a different set of excluded sectors. We must show that, with these contribution offers, no lobby has any incentive to deviate.

(a) Consider an industry $i \notin E(e)$. This industry is included in the FTA, and therefore contributes nothing to the government. Its net profit equals $\Pi_{\mathrm{iF}}$. In order to be excluded from $F$ the industry would have to raise its offer $C_{i E}$ above $\Pi_{i N}-\Pi_{i F}$, which would reduce its profits net of contributions. This industry might also raise its offer $\mathrm{C}_{\mathrm{iN}}$, in order to induce the government to reject the FTA entirely. But this too would be unprofitable, in view of (14). Finally, the lobby cannot gain by reducing $\mathrm{C}_{\mathrm{i}}$ in case it is positive, because the contribution is not paid in any event.

(b) Now consider an industry $i \in E(e)$. The definition of $E(e)$ implies that, for this industry, $0 \leq \mathrm{C}_{\mathrm{iE}} \leq \max \left(0, \Pi_{\mathrm{iN}}-\Pi_{\mathrm{iF}}\right)$. The lobby has no incentive to raise $\mathrm{C}_{\mathrm{iN}}$ in order 
to induce the government to reject the agreement, and no incentive to raise $\mathrm{C}_{\mathrm{iI}}$. Also, it has no incentive to raise $\mathrm{C}_{\mathrm{iE}}$, because the proposed contribution is large enough to ensure the industry a place on the list of excluded sectors. If $\mathrm{C}_{\mathrm{iE}}=0$, the lobby cannot reduce this bid any further. So we need only check that the industry has no incentive to reduce its bid $\mathrm{C}_{\mathrm{iE}}$ when this offer happens to be positive.

There are two cases to consider. First, suppose that \#E(e)<e. Then $\mathrm{J}=0$. In the event, if lobby $i$ were to reduce its bid below $C_{i E}=\max \left[0, a\left(W_{i F}-W_{i N}\right)\right]$, the government would remove industry $i$ from the list of exclusions. Second, suppose that $\# E(e)=e$. Then $J>0$. If lobby $i$ were to reduce its bid below $C_{i E}=\max [0$, $\left.\mathrm{a}\left(\mathrm{W}_{\mathrm{iF}}-\mathrm{W}_{\mathrm{iN}}\right)+\mathrm{J}\right]$, the government would gain by replacing $i$ by $\dot{j}$ on the list of excluded sectors, where $\hat{j}=\underset{j \notin E(e)}{\operatorname{argmax}}\left[\max \left(0, \Pi_{j N}-\Pi_{j F}+a W_{j N}-a W_{j F}\right)\right]$. In either case the net profits of lobby $i$ will not rise, since the definition of $E(e)$ ensures that $0 \leq C_{i E} \leq \max \left(0, \Pi_{i N}-\Pi_{i F}\right)$ for all $i \in E(e)$. It follows that $i$ cannot profitably deviate.

\section{$\underline{\text { Necessity }}$}

Now suppose that (14) is violated, but that the government nonetheless chooses $F$ with some set of exclusions $\dot{E}(e)$ such that \# $\dot{E}(e) \leq e$. There are two cases to consider. (a) Suppose $\hat{E}(e) \neq E(e)$. If $E(e) \subset \dot{E}(e)$ then $\# E(e)<e$, and there exists an $i \in \hat{E}(e)$ that is not in $E(e)$. It follows from the definition of $E(e)$ that for this $i, \Pi_{i F}-\Pi_{i N}+$ $\mathrm{a}\left(\mathrm{W}_{\mathrm{iF}}-\mathrm{W}_{\mathrm{iN}}\right)>0$. Since the government has chosen to exclude $\mathrm{i}$ from the agreement, it must be that $\mathrm{C}_{\mathrm{iE}}-\mathrm{C}_{\mathrm{iI}}+\mathrm{a}\left(\mathrm{W}_{\mathrm{iN}}-\mathrm{W}_{\mathrm{iF}}\right) \geq 0$. Together these inequalities imply $\Pi_{\mathrm{iN}}-\mathrm{C}_{\mathrm{iE}}<\Pi_{\mathrm{iF}}-\mathrm{C}_{\mathrm{iI}}$. It follows that lobby $i$ would prefer not to be excluded from the FTA. By choosing $C_{i E}=0$ and $C_{i I}$ slightly below $\Pi_{i F}-\Pi_{i N}$, the industry can induce the government to drop it from the list of exclusions, in view of the fact that $\Pi_{\mathrm{iF}}-\Pi_{\mathrm{iN}}+\mathrm{a}\left(\mathrm{W}_{\mathrm{iF}}-\mathrm{W}_{\mathrm{iN}}\right)>0$. This contradicts the supposition that $\mathrm{F}$ with exclusions $\hat{E}(e)$ is a unilateral stance. On the other hand, if $\hat{E}(e)$ is not a subset of $E(e)$, then there 
exists an industry $i \in E(e)$ that is not excluded from the agreement and an industry $\hat{i} \in \hat{E}(e)$ that is not in $E(e)$. By the definition of $E(e)$ industry $i$ can raise its $C_{i E}$ to slightly below $\Pi_{\mathrm{iN}}-\Pi_{\mathrm{iF}}$, and thereby ensure itself a place on the list of exclusions instead of industry $\hat{\mathrm{i}}$. Since this deviation would increase its net profits, there can be no unpressured stance with $R=F$ and $\hat{E}(e) \neq E(e)$.

(b) $\dot{E}(e)=E(e)$. Since the government chooses $R=F$ with the set of excluded sectors $E(e)$ and $C_{i I}=0$ for all included sectors in an unpressured stance, it follows that $\underset{\mathrm{i} \in \mathrm{E}(\mathrm{e})}{\Sigma} \mathrm{aW} \mathrm{WN}_{\mathrm{iN}}+\underset{\mathrm{i} \notin \mathrm{E}(\mathrm{e})}{\Sigma} \mathrm{aW} \mathrm{W}_{\mathrm{iF}}+\underset{\mathrm{i} \in \mathrm{E}(\mathrm{e})}{\Sigma} \mathrm{C}_{\mathrm{iE}} \geq \underset{\mathrm{i}}{\sum a W_{\mathrm{iN}}}+\underset{\mathrm{i}}{\sum \mathrm{C}_{\mathrm{iN}}}$. This and the fact that (14) is violated implies that

$$
\max \left[0, \max _{i \notin E(e)}\left(\Pi_{i N}-\Pi_{i F}\right)\right]-\sum_{i}^{\Sigma} C_{i N}>C-\sum_{i \in E(e)}^{\Sigma} C_{i E}
$$

For lobby $\mathrm{j} \notin E(e), C_{j E} \leq \max \left(0, \Pi_{j N}-\Pi_{j F}\right)$, because we have ruled out weakly dominated strategies. Therefore, lobby $i \in E(e)$ would never bid more than $C_{i E}=$ $\max \left[0, a\left(W_{i F}-W_{i N}\right)+J\right]$, because such a bid would ensure it a place on the list of excluded sectors, and a still higher can be profitably reduced. It follows that the righthand side of $(A 1)$ is non-negative, and therefore that

$$
\max \left[0, \max _{i \notin E(e)}\left(\Pi_{i N}-\Pi_{i F}\right)\right]>\sum_{i} C_{i N}
$$

Inequality (A2) ensures the existence of a lobby $\mathrm{j} E(\mathrm{e})$ that could raise its contribution $\mathrm{C}_{\mathrm{jN}}$ to $\hat{\mathrm{C}}_{\mathrm{jN}}$ slightly below $\max \left[0, \underset{\mathrm{i} \notin \mathrm{E}(\mathrm{e})}{\max }\left(\Pi_{\mathrm{iN}}-\Pi_{\mathrm{iF}}\right)\right]$, so that: $(\mathrm{a}) \Pi_{\mathrm{jN}}-\hat{\mathrm{C}}_{\mathrm{jN}}>\Pi_{\mathrm{jF}}$; and (b) if $j$ replaces $C_{j N}$ with $\dot{C}_{j N}$ and the other lobbies do not change their contributions, the government prefers $N$ to $F$ with exclusions $E(e)$. This contradicts the supposition that $\mathrm{F}$ is an unpressured stance.

It follows that (14) is necessary for the existence of an unpressured stance. 
Table 1

Outcomes Under an FTA $\left(\tau_{i}^{A}>\tau_{i}^{B}\right)$

$\begin{array}{lll}\text { Enhanced } & \underline{\text { Intermediate }} & \underline{\text { Reduced }} \\ \text { Protection } & \underline{\text { Protection }}\end{array}$

A imports from R.O.W.?

yes

no

no

B consumes own output?

no

no

yes

Produ cer price in A

Consumer price in $\mathrm{A}$

Produ cer price in $B$

$\begin{aligned} \tau_{i}^{\mathrm{A}} & >\tau_{\mathrm{i}}^{\mathrm{B}} \\ & <\tau_{\mathrm{i}}^{\mathrm{A}}\end{aligned}$

$\tau_{\mathrm{i}}^{\mathrm{B}}$

Consumer price in $\mathrm{B}$

$\tau_{i}^{B}$

${ }^{\mathrm{B}} \mathrm{i}$

$\tau_{\mathrm{i}}^{\mathrm{B}}$ 
Figure 1

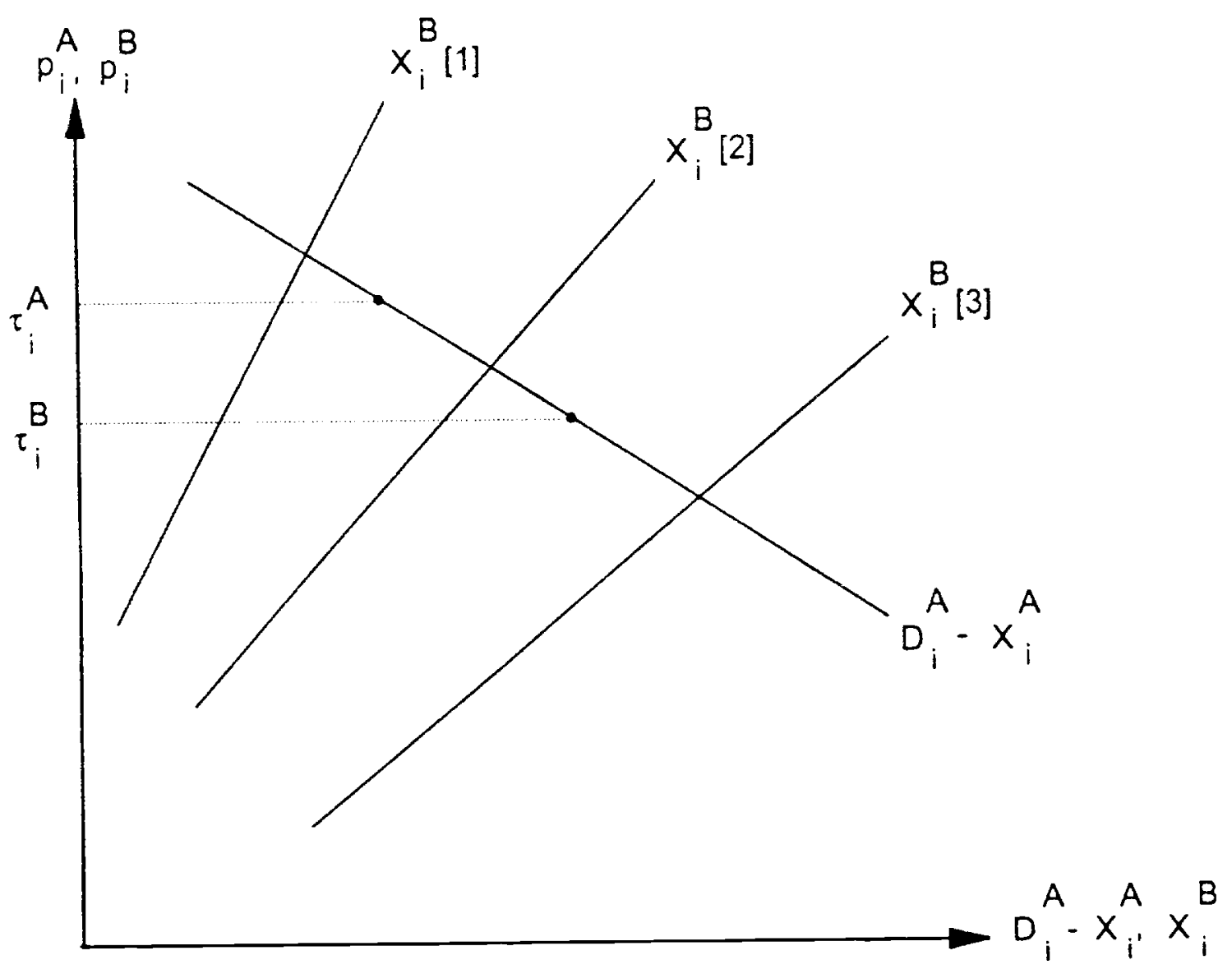


Figure 2

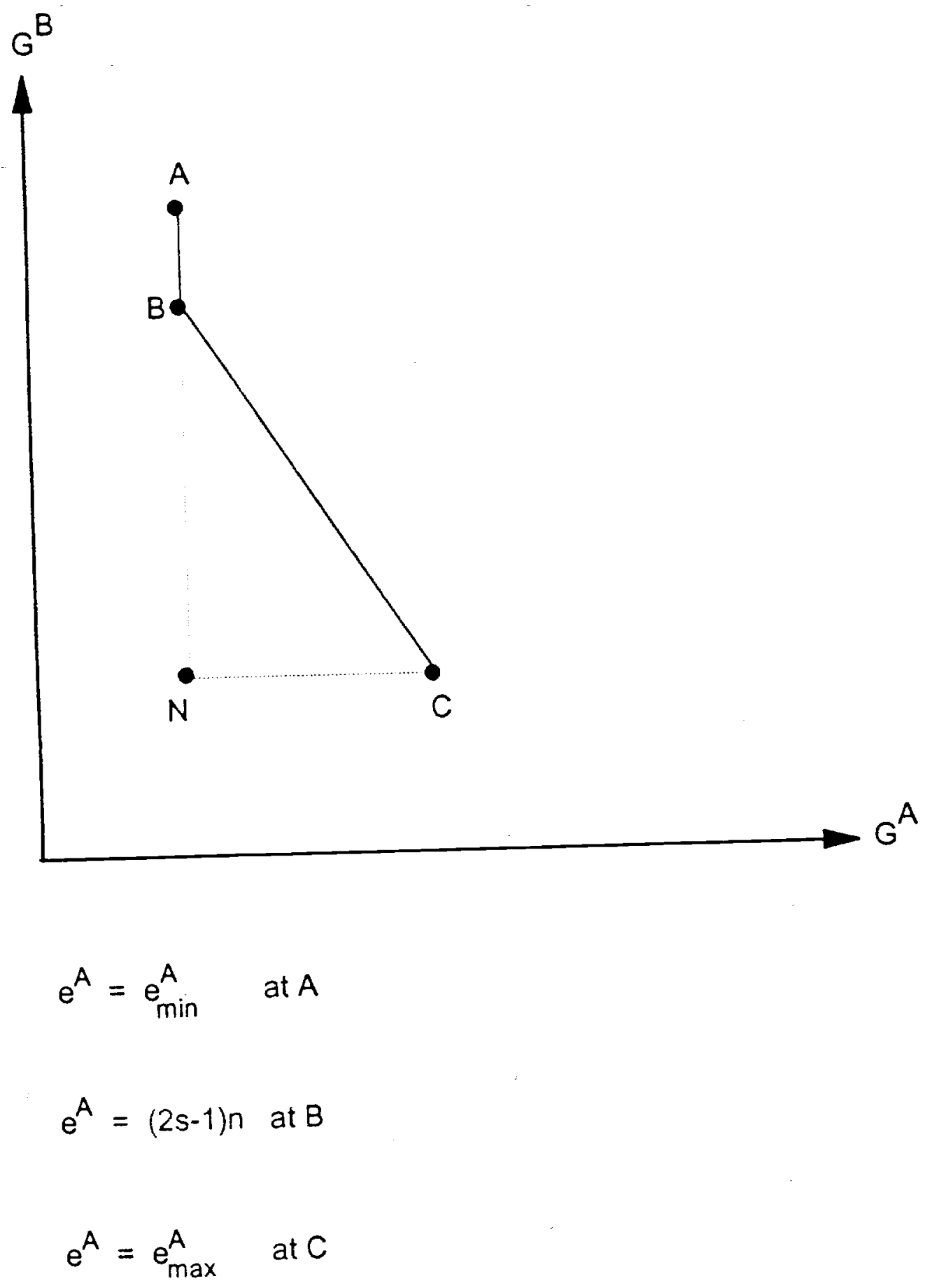

